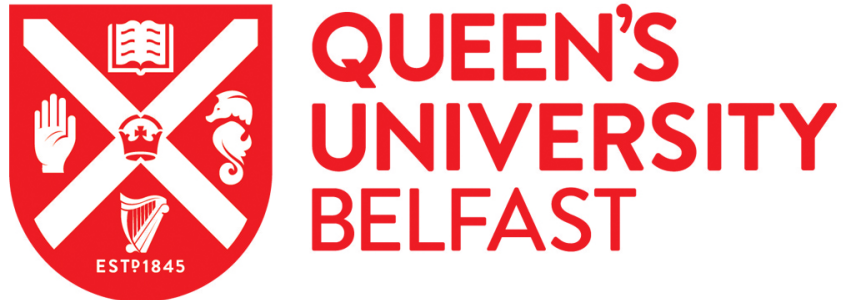

\section{Stock structure of Atlantic herring Clupea harengus in the Norwegian Sea and adjacent waters}

Pampoulie, C., Slotte, A., Óskarsson, G. J., Helyar, S. J., Jónsson, Á., Ólafsdóttird, G., Skírnisdóttir, S.,

Libungan, L. A., Jacobsen, J. A., Joensen, H., Nielsen, H. H., Sigurdsson, S. K., \& Daníelsdóttir, A. K. (2015).

Stock structure of Atlantic herring Clupea harengus in the Norwegian Sea and adjacent waters. Marine Ecology: Progress Series, 522, 219-230. https://doi.org/10.3354/meps11114

Published in:

Marine Ecology: Progress Series

Document Version:

Peer reviewed version

Queen's University Belfast - Research Portal:

Link to publication record in Queen's University Belfast Research Portal

Publisher rights

Copyright 2015 Inter Research.

\section{General rights}

Copyright for the publications made accessible via the Queen's University Belfast Research Portal is retained by the author(s) and / or other copyright owners and it is a condition of accessing these publications that users recognise and abide by the legal requirements associated with these rights.

Take down policy

The Research Portal is Queen's institutional repository that provides access to Queen's research output. Every effort has been made to ensure that content in the Research Portal does not infringe any person's rights, or applicable UK laws. If you discover content in the Research Portal that you believe breaches copyright or violates any law, please contact openaccess@qub.ac.uk. 
2 Stock structure of Atlantic herring (Clupea harengus L.) in the Norwegian

3 Sea and adjacent waters

4

5

6 Christophe Pampoulie ${ }^{1}$, Aril Slotte ${ }^{2}$, Guðmundur J. Óskarsson ${ }^{1}$, Sarah J. Helyar ${ }^{3}$, 7 Ásbjörn Jónsson ${ }^{3}$, Guðbjörg Ólafsdóttir ${ }^{3}$, Sigurlaug Skírnisdóttir ${ }^{3}$, Lísa Anne

8 Libungan $^{4}$, Jan Arge Jacobsen ${ }^{5}$, Hóraldur Joensen ${ }^{6}$, Henrik Hauch Nielsen ${ }^{7}$, Sindri Karl

$9 \quad$ Sigurðsson $^{8}$, Anna Kristin Daníelsdóttir ${ }^{3}$

10 
ABSTRACT: The genetic structure of Atlantic herring Clupea harengus was investigated in its north-easterly distribution at the Norwegian Sea and adjacent waters, using 23 neutral and one non-neutral (Cpa111) microsatellite loci. Fish from the two main suspected populations, the Norwegian spring-spawning herring (NSSH) and the Icelandic summer-spawning herring (ISSH), were collected at spawning locations/seasons from 2009 to 2012. Samples were also collected from Norwegian autumn spawning locations and from different local Norwegian fjords such as inner part of Trondheimsfjorden, Lindås pollene, Landvikvannet and Lusterfjorden, as well as from suspected Faroese spawning components. The observed level of genetic differentiation was significant but low $\left(F_{\mathrm{ST}}=0.007\right)$ and mostly attributable to the differentiation of the local Norwegian fjord populations. The locus Cpa111, which was detected to putatively be under positive selection, exhibited the highest $F_{\mathrm{ST}}$ value, $\left(F_{\mathrm{ST}}=\right.$ 0.044). The observed genetic patterns were robust to exclusion of this locus. Landvikvannet herring was also genetically distinguishable from the three other fjord populations. In addition, the present study does not support genetic structuring among the Icelandic summerspawning herring and the Norwegian spring-spawning herring.

KEY WORDS: Atlantic herring, Norwegian Sea, Norwegian fjords, microsatellite loci, adaptation, gene flow. 
Several approaches have been used to understand the population structuring of marine taxa from life-history (Einarsson 1951, Ricklefs \& Wikelski 2002, Arai et al. 2006, Curtis \& Vincent 2006, Clarke et al. 2007, ,Silva et al. 2013) and tracking studies (Fridriksson \& Aasen 1950, Fritsch et al. 2007, Wood et al. 2007, Donaldson et al. 2008, Tamdrari et al. 2012a,

Tamdrari et al. 2012b, Thorsteinsson et al. 2012, Whitlock et al. 2012), to population dynamics (Amilhat \& Lorenzen 2005, Syrjänen et al. 2008, Jung et al. 2012, Pampoulie et al. 2012). However, in the last 20 years one of the most common approaches employed to understand population structuring has been the indirect estimation of gene flow and migration rates as inferred from genetic markers (Carvalho \& Hauser 1994, Hauser \& Carvalho 2008,

Reiss et al. 2009). In the marine environment, neutral genetic markers such as microsatellite loci have been extremely useful to complement other means of inferring population differentiation such as life-history studies (Smith et al. 2002, Conover et al. 2006; Higgins et al. 2010), as well as to understand the complex population dynamics of several marine species (Ruzzante et al. 2006, Bradbury et al. 2010, Pampoulie et al. 2012). Yet, such information are prerequisites for devising sustainable management and conservation measures for exploited species (Hutchinson 2008). Moreover, the discovery of microsatellite loci showing signatures of selection (e.g. Nielsen et al. 2006) has changed our perception about genetic structuring of marine populations. The combined use of neutral and non-neutral loci has potential to yield (Hauser \& Carvalho 2008).

The Atlantic herring Clupea harengus is a typical marine pelagic species which exhibits 
Sea. These discrete stocks also exhibit large distance migration from their spawning-areas to common feeding grounds (Dragesund et al. 1997, McQuinn 1997, Óskarsson et al. 2009) where mixed fisheries occur. Atlantic herring has, indeed, a long history of fishing and has been a commercially important species over nearly two centuries (Smylie 2004). It occurs on both side of the North Atlantic and has exhibited considerable fluctuations in stock size and spatial distribution in the last hundred years, marked by drastic concurrent collapses in several stocks in the 1960's (Jakobsson 1980, Toresen \& Østvedt 2000, Overholtz 2002, DickeyCollas et al. 2010). Contrary to the Atlantic cod and other marine resources, most of the herring stocks recovered from collapses over periods of varying length, and are today subject to intense fishing pressure. Today, the largest Atlantic herring stock is the Norwegian springspawning herring (NSSH), which is distributed from the southern part of Norway to the Barents Sea and from the Norwegian Sea to the Northeast coast of Iceland. Prior to the collapse of NSSH in the late 1960s, a part of this stock spawned on the banks east of the Faroe Islands, fed over a wide area in the NE-Atlantic and had wintering grounds off the east coast of Iceland (Jakobsson 1980, Dragesund et al. 1997), therefore mixing with the Icelandic summer-spawning herring (ISSH) and Icelandic spring-spawning herring (ISPH), the latter which has not recovered from it's collapse in the late 1960s (Jakobsson 1980). After the collapse of NSSH, the stock was primarily confined to the coastal areas along the western coast of Norway (Dragesund et al. 1997). Since the 1970s, the stock has slowly recovered with a maximum level in 2010 of around 10 million tons (ICES 2012) and again feeding in the open ocean between Norway, Faroe Islands and Iceland (Fig. 1). Three different management units are currently considered for stock assessment in the Norwegian Sea and adjacent waters: the Norwegian spring-spawning herring (NSSH), the Icelandic summerspawning herring (ISSH) and the North Sea autumn spawning herring (NSAH). In addition, the occurrence of Norwegian local spring-spawning herring (NLSSH) (Johannessen et al. 
2009, Silva et al. 2013) mainly spawning in local fjords and of a Norwegian autumnspawning (NASH) herring has been mentioned (Husebo et al. 2005). Moreover, the presence of a spring-spawning herring (FSSH) and an autumn-spawning (FASH) herring have been suggested in Faroese waters. So far, the discrimination of these stocks is primarily based on spawning time and location.

The genetic structure of the Atlantic herring has received considerable attention in recent years, as the species has been shown to exhibit a complex population dynamics and lifehistory variations within the management units (Husebo et al. 2005), as well as a relatively low level of differentiation among isolated local populations overlapping geographically during feeding migrations (Bekkevold et al. 2005, Jørgensen et al. 2005, Mariani et al. 2005, Ruzzante et al. 2006, Gaggiotti et al. 2009, André et al. 2011, Lamichhaney et al. 2012, Corander et al. 2013, Teacher et al. 2013). However, most of these studies performed to genetically discriminate stocks and assess their contribution to mixed fisheries have been focusing on the southern distribution of the Atlantic herring.

The conservation and sustainable exploitation of the herring stocks in the Norwegian Sea and adjacent waters crucially depends on our understanding of genetic structuring and interactions of the potentially distinct populations in this area. Until now, the genetic differentiation among NSSH and ISSH management units and/or subpopulations has never been investigated, even with already available microsatellite loci (O'Connel et al. 1998, McPherson et al. 2001, Miller et al. 2001, Olsen et al. 2002, Libungan et al. 2012). Hence, it is not currently known if and which genetic markers can be used to discriminate stocks occurring in this area, and thereby to assess their respective contributions to mixed-stock fisheries of this commercially highly important species. Here we present one of the first genetic studies of the Norwegian Sea and adjacent waters herring populations using 24 microsatellite loci of which several are known to be under selection in other herring populations (Gaggiotti et al. 2009, 
André et al. 2011, Teacher et al. 2013). Our aims were three-fold- First, to attempt to confirm

121 the aforementioned reproductive isolation (spawning time and location) between different herring populations around the Norwegian Sea. Second, to assess the aforementioned uniqueness of the Norwegian fjord spawning herring, and third, to compare neutral to nonneutral genetic variation in order to detect potential signatures of selective differentiation.

\section{MATERIALS AND METHODS}

\section{Sampling areas and protocol}

In all, 1258 Atlantic herring were collected at several spawning locations in the Northeast Atlantic from 2009 to 2012 during local spawning seasons (Fig. 2, Table 1) including samples

130 from different local Norwegian fjords such as Trondheimsfjorden (inner part of Trondheim

131 fjord), Lindås pollene, Landvikvannet and Lusterfjorden as well as suspected FASH and FSSH. Individuals fish were selected for genotyping owing to their reproductive status using the following maturity scale (see Table 1 for the percentage of breeding fish per sample): $1-2$

134 immature, 3-5 maturing, 6 spawning, 7 recently spawned and 8 resting (Bowers \& Holliday 135 1961, Anonymous 1962).

136 Genetic samples were collected from muscle or fin clips preserved in $99 \%$ ethanol. Samples were genotyped at 24 microsatellite loci: msild12, msild13, msild17, msild24, msild27 and msild32 (Libungan et al. 2012), Cha1017, Cha1020, Cha1027, Cha1059 and Cha1202

139 (McPherson et al. 2001), Cha4 (Cpa4 in Miller et al., 2001), Cha17, Cha63 and Cha113 140 (O'Connel et al. 1998), Cpa101, Cpa102, Cpa103, Cpa104, Cpa108, Cpa111, Cpa112, Cpa113 141 and Cpa114 (Olsen et al. 2002).

142 DNA was extracted either from muscle, or fin clips by AGOWA mag Midi DNA Isolation 143 Kit (AGOWA Gmbh) or hot shot DNA extraction method (Montero-Pau et al. 2008). The 144 forward primers of each microsatellite loci were labelled with one fluorescent dye (6-FAM, 
145 VIC, NED or PET). Polymerase chain reactions (PCR) were performed in Multiplexes

146 (Supplementary Table S1) as follows: $10 \mu \mathrm{l}$ volume containing 2-3 $\mu \mathrm{l}$ DNA (10-100 ng/ $\mu \mathrm{l})$,

$147 \quad 0.80 \mu \mathrm{l}$ of $\mathrm{dNTP}(10 \mathrm{mM}), 0.6-1.2 \mathrm{U}$ Teg polymerase (Matís Ltd., Taq comparable, see

148 Ólafsson et al. 2010), $1 \mu \mathrm{l}$ of 10x buffer (Matís Ltd.), 0.03-0.25 $\mu 1$ of a 50:50 ratio of labelled

149 forward $(100 \mu \mathrm{M})$ and reverse $(100 \mu \mathrm{M})$ primer tagged on the 5 '-end with a GTTTCTT PIG-

150 tail (Brownstein et al. 1996) adding $1 \mu$ betaine (5 M) when improvement of DNA

151 amplification was needed. Samples were analysed on an ABI PRISM 3730 sequencer using 152 the GeneScan-500 LIZ size standard and genotyped with GeneMapper v4.0 (Applied

153 Biosystems).

\section{Genetic analyses}

As the neutrality assumption of genetic markers is crucial for the conclusion drawn from genetic data, we applied the coalescent-based simulation methods of Beaumont and Nichols (Beaumont \& Nichols 1996) to detect potential outlier loci (loci under selection). Coalescent simulations were performed with the software LOSITAN (Antao et al. 2008) with samples of

160 the same size as the observed samples assuming an island model with 100 islands. A total of

161100,000 independent loci were generated with the infinite allele mutation model and the "neutral" mean $F_{\mathrm{ST}}$ function (outlier loci were excluded to calculate the initial mean $F_{\mathrm{ST}}$ ).

163 Simulated distribution of $F_{\mathrm{ST}}$ values conditional to heterozygosity under a neutral model were 164 obtained and thus compared to observed $F_{\mathrm{ST}}$ values to identify potential outlier loci. In 165 addition, we performed outliers' tests in BayeScan (Foll \& Gaggiotti 2008), which allows for 166 different demographic histories and drift between populations. BayeScan was run with 50,000

167 Burn-in, 50 thinning, a sample size of 1,000, 300,000 iterations, 20 pilot runs with a length of 1685,000 and a FDR of 0.05. Outliers which were identified with both methods (LOSITAN and 169 BayeScan) were considered to be under selection. 
A statistical power analysis of the microsatellite loci was performed to assess whether genetic structure could be detected among the North Atlantic samples with the developed sampling strategy and the genetic markers used. The Norwegian local spring-spawners samples which showed the highest level of differentiation in our samples' collection were

174 therefore excluded for this analysis. The statistical power of the microsatellite loci was 175 estimated using the program POWSIM (Ryman \& Palm 2006), which assesses the $\alpha$ (type I) 176 error (the probability of rejecting $H o$ when it is true) and the power of the genetic design 177 performed using information on sample sizes, number of samples, number of loci, and allele 178 frequencies for any hypothetical degree of true differentiation quantified as $F_{\text {ST }}$ (Ryman \& 179 Palm 2006). The significance of the tests was assessed by Fisher's exact tests as well as by $\chi^{2}$ 180 tests. These tests were performed without the NLSSH samples.

181 Genetic diversity of samples (evaluated using allele frequencies), observed and expected 182 heterozygosities. and deviations from Hardy-Weinberg equilibrium (HWE) were calculated in GENEPOP'007 (Rousset 2008). Population differentiation was estimated both between pairwise samples and overall using the unbiased $F_{\mathrm{ST}}$ estimator $\theta$ of Weir \& Cockerham

185 (1984). Statistical significance was assessed using the exact G-test implemented in 186 GENEPOP'007.

187 To visualize the level of genetic differentiation among samples, the pairwise estimates of $188 F_{\text {ST }}$ were lotted using the multidimensional scale (MDS) function in R (cmdscale, Team RC 189 2012).

190 The number of subpopulations $(K)$ potentially contained in our samples set was assessed 191 using STRUCTURE (Pritchard et al. 2000) with no prior information on sample location.

192 STRUCTURE was run using 350,000 burn-in and 500,000 iterations for 10 independent runs 193 for $K=1$ to 10 using an admixture model with correlated allele frequencies. The results were 194 scrutinized in STRUCTURE HARVESTER (Earl \& vonHoldt 2012) in order to estimate the 
optimal number of $K$ using the Evanno's method (Evanno et al. 2005). DISTRUCT was then

196 used to visualise the data (Rosenberg 2004). As STRUCTURE is likely to detect the highest

197 level of differentiation among the samples, we conducted a hierarchical analysis by

198 performing similar STRUCTURE runs on detected populations $(K)$ containing several 199 samples.

\section{RESULTS}

\section{Genetic diversity}

Biological information retrieved from the samples is listed in Table 1. Except sample 1 and 14, most of the fish collected were ready to spawn (maturity stage 5) or spawning (maturity stage 6) (Table 1). The number of alleles per locus was high, ranging from 9 (Cap111) to 63 (msild24; data not shown). The unbiased expected heterozygosity per sample ranged from 0.836 (NSSH4) to 0.850 (FSSH) (Supplementary Table S2). Genotypic proportion were out of HWE in 26 of 336 exact tests, of which two remained significant after the Bonferroni correction for multiple tests, and were not attributable to any loci or samples

210 (Supplementary Table S2).

\section{Outlier tests}

213 Simulations for detection of outlier loci performed in LOSITAN suggested that two loci 214 fell outside the $95 \%$ confidence interval; locus Cpa111 and msild 13 were suggested to be 215 under positive selection (Supplementary Table S3). Using a 99\% confidence interval, only 216 Cpa111 was suggested to be under positive selection (Supplementary Table S3). BayeScan 217 simulations only identified Cpa111 as putatively under selection (Supplementary Table S4). 218 Hence, all following structure analyses were performed with and without the outlier locus 219 (Cpa111), except the statistical power test. 


\section{Statistical power of the microsatellite loci}

Excluding the Norwegian local spring-spawners samples, the estimate of the statistical $\alpha$

(type I) error rate (i.e. the probability of rejecting the null hypothesis of genetic homogeneity 224 when it is true), varied from 0.075 with Fisher's exact tests to 0.077 with $\chi^{2}$ tests (Supplementary Table S5), which is slightly higher than the 5\% limit for significance, but still at a reasonable level (Ryman \& Palm 2006). The simulations on the power analysis of the microsatellite loci revealed that the combination of the microsatellite loci and sample sizes used, conferred a statistical power sufficient to detect any level of differentiation among the North Atlantic samples collected, equal to or above $F_{\mathrm{ST}}=0.001$ with a maximum power 230 (Supplementary Table S5).

\section{Population structure}

The overall genetic estimates revealed a highly significant $F_{\mathrm{ST}}\left(F_{\mathrm{ST}}=0.007, p<0.001\right.$, 95\% CI: $0.005-0.0010)$ and $F_{\text {IS }}\left(F_{\text {IS }}=0.021, p<0.001,95 \%\right.$ CI: 0.012-0.031). Locus Cpa111 exhibited the highest $F_{\mathrm{ST}}$ value $\left(F_{\mathrm{ST}}=0.044\right)$, while all other loci exhibited lower similar values. Out of 91 pairwise $F_{\mathrm{ST}}$ comparisons, 53 were significantly different from zero (Supplementary Table S6), and 50 remained significant after Bonferroni correction. All significant 50 comparisons involved samples from Norwegian local spawning herring (NLSSH). The pattern of significance of pairwise $F_{\mathrm{ST}}$ comparisons remained similar when the Cpa111 locus was removed (Supplementary Table S7).

The multidimensional scale analysis (MDS) for all loci confirmed these results and 242 revealed that all NLSSH samples were highly distinct from the Northeast Atlantic ones. 243 NLSSH samples were also clearly distinct from each other apart from sample 13 and 14 (Fig. 
3a). The same pattern was observed when the outlier locus was excluded from the analysis (Fig. 3b).

Using all loci, the Bayesian cluster analysis (STRUCTURE) revealed that the most likely number of populations contained in our samples was for $K=2$ (Fig. 4a, Supplement Fig. S1), both with $\operatorname{LnP}(k)$ values and $\Delta K$ (Evanno et al. 2005). One cluster was composed of all Northeast Atlantic samples while the second one was composed of the Norwegian fjord samples (NLSSH). The hierarchical analysis of the North Atlantic cluster did not reveal any further structuring (Supplementary TableS8) while it detected two additional clusters in the fjord samples (NLSSH), one composed of sample 12 (Landvikvannet) and one composed of the three other fjord samples (samples 11, 13 and 14: Supplementary Table S8, Fig. S2).

254 Further analyses of the second cluster (samples 11, 13 and 14) did not reveal any additional 255 structuring (Supplementary Table S8, Fig. S3).

Using the neutral loci only, the most likely number of cluster detected with STRUCTURE was for $K=3$ (Fig. 4b, Supplement Fig. S3) both with $\operatorname{LnP}(k)$ values and $\Delta K$ (Evanno et al. 2005). The first cluster was composed of all samples from the Northeast Atlantic, the second of the sample collected in Landvikvannet (sample 12), and the third one of samples collected 260 in other fjords (samples 11, 13 and 14). Additional hierarchical analysis of the third cluster 261 (samples 11, 13 and 14) did not reveal any substructure in these fjords, i.e. the most likely 262 number of cluster was $K=1$ (Supplementary Table S9). The same result was observed for the 263 first cluster, i.e. the samples collected in Northeast Atlantic (Supplementary Table S9).

\section{DISCUSSION}

\section{Global genetic structure}

Genetic markers have been intensively used to assess genetic structure of the Atlantic herring in its south-eastern distribution, but we are among the first ones (but see: Shaw et al. 
1999) to investigate it in the Norwegian Sea and surrounding waters, including the Norwegian

270 local spawning herring. The results of this study showed that, even with 23 neutral and one 271 non-neutral microsatellite loci, the Atlantic herring did not exhibit any significant genetic 272 differentiation among stocks across the investigated area, although the Norwegian local273 spawning herring samples were indeed genetically differentiated from all other samples. 274 Although one can suggest that STRUCTURE analyses might not correctly uncover genetic 275 pattern due to the observed low level of differentiation, this study presents a robust 276 interpretation of the developed statistical approaches based on a combination of $F_{\mathrm{ST}}$ values, MDS and STRUTURE runs, which strongly support the observed genetic pattern.

The populations of Atlantic herring which have been genetically studied in the southeastern distribution (Jørgensen et al. 2005, Mariani et al. 2005, Ruzzante et al. 2006, Gaggiotti 280 et al. 2009, André et al. 2011), exhibited low level of differentiations except at some 281 hitchhiking microsatellite loci such as Cpa112 and Her14 (Gaggiotti et al. 2009, Teacher et al. 282 2013). Genetic differentiation is indeed expected to be more pronounced at coding (or linked) loci, especially in large populations in which even weak selection might override effects of 284 genetic drift (Gaggiotti et al. 2009). Microsatellite loci and other genetic markers under 285 selection (like SNPs) were found to show some striking differentiation among herring 286 populations (Lamichhaney et al. 2012, Nielsen et al. 2012, Corander et al. 2013). In the 287 current study, we failed to detect any genetic structuring among the large Northeast Atlantic 288 herring populations. NSSH is by far the largest and ISSH among the largest herring 289 populations of the Northeast Atlantic, and their effective population size $\left(N_{\mathrm{e}}\right)$ is expected to be 290 very large, and hence, provides a probable explanation for lack of genetic differentiation. The 291 potential combination of high $N_{\mathrm{e}}$ and considerable level of gene flow among herring 292 populations have been suggested to hinder the detection of structure among local populations 293 of this species using neutral markers (Bekkevold et al. 2005, Mariani et al. 2005). However, 
an earlier microsatellite loci study has discovered genetic differences between ISSH and

295 NSSH at neutral loci (Shaw et al. 1999), but only a small number ( $\mathrm{n}=4$ loci) of microsatellite loci and a relatively small sample collection were used in that study. The North Atlantic herring exhibits large effective population size and such a low number of microsatellite might not be sufficient to uncover the genetic pattern of this species. For such a species, a higher number of samples and loci are necessary to fully fathom genetic structure (see Ruzzante 1998 for bias and sampling variance when using microsatellite loci).

Another potential explanation for the lack of significant genetic differentiation among Northeast Atlantic populations of herring might be found from the low power of the microsatellite loci resolving population structuring, as well as the quality of the sampling design (Ryman \& Palm 2006). However, the power analysis of the 24 microsatellite loci used revealed that the estimated $\alpha$ (type I error) was reasonably low, and that the sampling design should have been sufficient to detect level of differentiation of $F_{\mathrm{ST}}=0.001$ if it was present (see Table 5). Until now, the distinction of ISSH vs. NSSH is mainly based on morphological, physiological and biological characteristics (Einarsson 1951, Jakobsson et al. 1969). Single nucleotide Polymorphisms (SNPs) have recently been developed and seem to be promising for such marine species with large $N_{\mathrm{e}}$ and complex biodynamic, especially when investigating functionally important genetic loci (Helyar et al. 2012, Limborg et al. 2012, Nielsen et al. 2012, Corander et al. 2013, Teacher et al. 2013).

Most of the local populations of herring included in this study (NLSSH, samples 11, 13, and 14) have recently been studied in terms of reproductive investment and growth (Silva et al. 2013). The stationary herring of Trondheimsfjord was described in the early 1900's and suggested to be distinct from NSSH (Broch 1908, Runnstrom 1941, see Silva et al. 2013 for a full description). An allozyme studiy of samples from ISSH, NSSH and two Norwegian fjords (including Trondheimsfjord) also only found significant genetic differentiation between the 
stationary Trondheimsfjord herring and all other localities (Turan et al. 1998). Recent lifehistory studies have suggested that Trondheimsfjord herring was "a few of many potentially genetically unique populations with phenotypic adaptations to a stationary life in well defined environment..." (Silva et al. 2013). Trondheimfjord (Broch 1908, Runnstrom 1941, Sørensen 2012, Silva et al. 2013), Lusterfjord (Aasen 1952), Lindås pollene (Lie et al. 1978, Johannessen et al. 2009, Silva et al. 2013) and Landvikvannet herrings (Silva et al. 2013, Eggers 2013) have long been considered to belong to self-sustaining and rather stationary populations characterized by a lower vertebral count, slower growth, lower length at maturity, shorter life span and a higher relative fecundity than the migratory oceanic NSSH. The fact that these populations with apparent adaptations to life mostly spent inside fjord areas have been known to exist for up to a century suggests that they may be genetically unique as

330 supported by the present study. In addition, the analysis of the fjord samples revealed that Landvikvannet sample was genetically distinguishable from all other fjord samples. This is most likely linked to the potential mixture with oceanic herring at various life stages that differ between Landvikvannet herring and the other fjord populations. The herring in Lindås

334 pollene, Lusterfjord and Trondheimfjord may all mix with NSSH herring drifting into the

335 fjord areas as larvae from spawning grounds outside the fjord areas. Albeit most of NSSH 336 grow up in the Barents Sea, portions always tend use the fjords as nursery areas until age of two years (Holst \& Slotte 1998). Even though the NSSH is genetically tuned to leave the 338 fjords by two years age to grow further and join the adult spawning stock in the open ocean, 339 one cannot exclude the possibility that some choose to stay, especially if there is numerical 340 domination of the local herring of the same size (Huse et al. 2002). Hence, over time gene 341 flow might have occurred consistently between the NSSH and local fjord populations. Recent 342 studies from Lindås pollene even indicate that gene flow among adult NSSH and local herring 343 might explain the evolution of the fjord population's life history traits from the 1960s to the 
2000s towards a regime with higher growth and higher length at maturity (Langård 2013). In

345 Landvikvannet the link to NSSH is not clear as this local fjord is outside the observed 346 spawning area of NSSH. In the latter, local herring might mix with coastal spring spawners or

347 even with Western Baltic spring spawners (WBSS) migrating into the Skagerrak area and 348 feeding close to the Norwegian coast during summer. Landvikvannet was artificially 349 connected to the open sea through a $3 \mathrm{~km}$ long canal in 1887 , and has been a brackish 350 environment ever since with anoxic condition at depths below $4 \mathrm{~m}$. Therefore, the observed 351 genetic differences among Landvikvannet herring and the other fjords is likely due to the fact 352 that Landvikvannet was colonized by straying of WBSS herring already being adapted to low 353 salinity conditions. In fact the very low vertebral count in Landvikvannet herring perfectly 354 equals that of WBSS (55.7). However, data on vertebral counts and growth from the most 355 recent study in Landvikvannet (2012) indicate that NSSH herring has also recently visited this 356 area, mixing with a group of coastal spring spawners and what is believed to be 357 Landvikvannet herring (Eggers 2013). The three groups occupy this ecological niche at 358 different times with some overlap in spawning stages. NSSH arrive first in March, while the 359 coastal spring spawners arrive in March-April and finally Landvikvannet herring peaks in 360 abundance in May. The genetic sample used in the present study was taken in May, which has 361 been the main sampling period since 1980s used as a basis for the suggestion of a local fjord 362 population. Given the results from 2012 further genetic studies are needed of the herring in 363 the area of Landvikvannet to be able to draw firm conclusions.

\section{Neutral vs. non neutral genetic markers}

While levels of differentiation ( $F_{\mathrm{ST}}$ 's) and their visual representation (MDS) tend to 367 suggest similar genetic patterns when all loci are included or when excluding Cpa111, the 368 primary results of the Bayesian cluster analysis would have resulted in fairly different 
conclusions based on these two approaches. In fact, the first Bayesian cluster analysis

370 including all loci supported a main differentiation between all fjords samples and all samples

371 collected around the Norwegian Sea, while the neutral loci analysis clearly distinguished one

372 additional cluster, the fjord sample from Landvikvannet (NLSSH, sample 12). On the

373 contrary, when all loci were used, the Bayesian cluster analysis could not detect differences

374 among the fjord samples without an additional hierarchical analysis. A closer look into

375 Cap111 (the locus under selection) allele frequencies (Fig. 6) revealed a clear shift in allele 376 frequencies among the fjords and the Northeast Atlantic populations (the former exhibited a

377 high frequency of allele-275 compared to the latter), but also a slightly different pattern in 378 Landvikvannet "sample" (NLSSH, sample 12) compared to the other fjord samples. Indeed, it 379 exhibited a higher frequency at allele-287 than any other fjords and Northeast Atlantic 380 samples, and did exhibit a somehow lower allele-275 frequency than the other fjord samples, 381 differences that the Bayesian cluster analysis did not catch except when an additional 382 hierarchical analysis was performed on the fjord samples. As suggested above, these observed 383 genetic differences among the fjord samples might be due to differences in their origin and 384 their respective interaction with NSSH but might also reflect potential different ongoing 385 genetic evolution of the fjords populations.

\section{Fisheries management}

In term of management, although the power analysis performed suggested that a relatively low level of differentiation would be detectable with our research design, we only detected

390 genetic differences among the North Atlantic and the Norwegian local populations. The combination of large effective population size and the relatively short time for divergence since the recovery of the North Atlantic populations might have precluded evolution of genetic differences. However, the herring populations in the investigated area are exhibiting 
394 different life-history patterns, which, in the absence of genetic evidence, should be integrated 395 (and are already) in fisheries management. The observed biological uniqueness of the 396 Norwegian local populations, and especially the exceptionality of Landvikvannet herring 397 should be investigated further to decipher their interactions with the NSSH component and 398 Western Baltic component to ensure appropriate management of herring stocks in future.

400 Acknowledgements. This research was supported by grants from the Working Group for 401 Fisheries Co-operation (AG-Fisk) of the Nordic Council of Ministers (HerMix project number 402 45-2011), the Icelandic Fisheries Research Fund (HerMix project number R007), the 403 Fisheries Research Fund of the Faroe Islands (Fiskivinnuroyndir, HerMix project number 404 201000742), the Icelandic Research Fund for Graduate Students RANNIS (Project number 405 100710001) and the Icelandic Student Innovation Fund RANNIS (project number 406 903100862). The FRS Marine Laboratory in Aberdeen, Scotland, UK, is acknowledged for 407 the provision of a herring sample west of Shetland. Bergur Poulsen, Havsbrún P/F, Faroe 408 Islands for their support and view from the industry. Sigurjón Arason at Matis is 409 acknowledged for his valuable contribution to the construction of the project and scientific 410 input. 
Aasen O, (1952) The Lusterfjord Herring and its environment. Fiskeridirektoratets Skrifter Serie Havundersøkelser 10:1-63

Amilhat E, Lorenzen K (2005) Habitat use, migration pattern and population dynamics of chevron snakehead Channa striata in a rainfed rice farming landscape. J Fish Biol 67:23-34

André C, Larsson LC, Laikre L, Bekkevold D, Brigham J, Carvalho GR, Dahlgren TG, Hutchinson WF, Mariani S, Mudde K, Ruzzante DE, Ryman N (2011) Detecting population structure in a high gene-flow species, Atlantic herring (Clupea harengus): direct, simultaneous evaluation of neutral vs putatively selected loci. Heredity 106:270-280

Anonymous (1962) Recommendations adopted by the Herring Committee. Rapp P.-V. Réun Cons Int Explor Mer 1:1-73 [Append.].

Antao L, Lopes A, Lopes RJ, Beja-Pereira A, Luikart G (2008) LOSITAN: a workbench to detect molecular adaptation based on a FST-outlier method. BMC Bioinfo 9:323-327

Arai T, Yang J, Miyazaki N (2006) Migration flexibility between freshwater and marine habitats of the pond smelt Hypomesus nipponensis. J Fish Biol 68:1388-1398

Beaumont M, Nichols RA (1996) Evaluating loci for use in the genetic analysis of population structure. Proc Roy Soc Lond B Biol Sci 263:1619-1626

Beaumont MA (2005) Adaptation and speciation: what can FST tell us? TREE 20:435-440

Bekkevold D, André C, Dahlgren TG, Clausen LA, Torstensen E, Mosegaard H, Carvalho GR, Christensen TB, Norlinder E, Ruzzante DE (2005) Environmental correlates of population differentiation in Atlantic herring. Evolution 59:2656-2668

Bowers AB, Holliday FGT (1961) Histological changes in the gonad associated with the reproductive cycle of the herring (Clupea harengus L.). Mar Res 5:1-16

Bradbury IR, Hubert S, Higgins B, Borza T, Bowman S, Paterson IG, Snelgrove PIVR, Morris CJ, Gregory RS, Hardie DC, Hutchings JA, Ruzzante DE, Taggart CT, Bentzen P (2010) Parallel adaptive evolution of Atlantic cod on both sides of the Atlantic Ocean in response to temperature. Proc Roy Soc B Biol Sci 277:3725-3734

Broch H (1906) Foreløpig meddelelse om sildeundersøgelserne. Aarsberetning vedkommende Norges fiskerier for 1905:442-451

Broch H (1908) Norwegische heringsuntersuchen wahrend der jahre 1904-1906. Bergen Museums Årbok 1:1-9

Brownstein MJ, Carpten JD, Smith JR (1996) Modulation of non-templated nucleotide addition by Taq DNA polymerase: primer modifications that facilitate genotyping. Biotechniques 20:1004-1006, 1008-1010

Cano JM, Shikano T, Kuparinen A, Merilä J (2009) Genetic differentiation, effective population size and gene flow in marine fishes: implications for stock management. $\mathrm{J}$ Integrat Field Biol 5:1-10

Carvalho GR, Hauser L (1994) Molecular genetics and the stock concept in fisheries. Rev Fish Biol Fish 4:326-350

Clarke AD, Lewis A, Telmer KH, Shrimpton JM (2007) Life history and age at maturity of an anadromous smelt, the eulachon Thaleichthys pacificus (Richardson). J Fish Biol 71:1479-1493

Conover DO, Clarke LM, Munch SB, Wagner GN (2006) Spatial and temporal scales of adaptive divergence in marine fishes and the implications for conservation. J Fish Biol 69:21-47 
Corander J, Majander KK, Cheng L, Merilä J (2013) High degree of cryptic population differentiation in the Baltic Sea herring Clupea harengus. Mol Ecol 22:2931-2940

Curtis JMR, Vincent ACJ (2006) Life history of an unusual marine fish: survival, growth and movement patterns of Hippocampus guttulatus Cuvier 1829. J Fish Biol 68:707-733

Dickey-Collas M, Nash RDM, Brunel T, van Damme CJG, Marshall CT, Payne MR, Corten A, Geffen AJ, Peck MA, Hatfield EMC, Hintzen NT, Enberg Ka, Kell LT, Simmonds EJ (2010) Lessons learned from stock collapse and recovery of North Sea herring: a review. ICES J Mar Sci 67:1875-1886

Donaldson MR, Arlinghaus R, Hanson KC, Cooke SJ (2008) Enhancing catch-and-release science with biotelemetry. Fish Fish 9:79-105

Dragesund O, Johannessen A, Ultang O (1997) Variation in migration and abundance of Norwegian spring spawning herring (Clupea harengus L.). Sarsia 82:97-105

Earl DA, vonHoldt BM (2012) STRUCTURE HARVESTER: a website and program for visualizing STRUCTURE output and implementing the Evanno method. Cons Genet Res 4:359-361

Eggers F (2013) Metapopulation dynamics in Atlantic herring (Clupea harengus L.) along the coast of southern Norway and in the local area of Landvikvannet. Master of Science in Fisheries Biology and Fisheries Management. University of Bergen, 92 pp.

Einarsson H (1951) Racial analysis of Icelandic herrings by means of the otoliths. Rapports et Procés Verbaux des Réunions du Conseil Interntational pour l'Exploration de la Mer 128:55-74

Evanno G, Regnaut S, Goudet J (2005) Detecting the number of clusters of individuals using the software STRUCTURE: a simulation study. Mol Ecol 14:2611-2620

Foll M, Gaggiotti OE (2008) A genome-scan method to identify selected loci appropriate for both dominant and codominant markers: A Bayesian Perspective. Genetics 180:977993

Fridriksson A, Aasen O (1950) The Norwegian-Icelandic herring tagging experiments. Rep No 1. Fisk Dir Skr Ser Havunders 9:1-43

Fritsch M, Morizur Y, Lambert E, Bonhomme F, Guinand B (2007) Assessment of sea bass (Dicentrarchus labrax, L.) stock delimitation in the Bay of Biscay and the English Channel based on mark-recapture and genetic data. Fish Res 83:123-132

Gaggiotti OE, Bekkevold D, Jørgensen HBH, Foll M, Carvalho GR, Andre C, Ruzzante DE (2009) Disentangling the effect of evolutionary, demographic, and environmental factors influencing genetic structure of natural populations: Atlantic herring as a case study. Evolution 63:2939-2951

Hauser L, Carvalho GR (2008) Paradigm shifts in marine fisheries genetics: ugly hypotheses slain by beautiful facts Fish Fish 9:333-362

Helyar SJ, Limborg MT, Bekkevold D, Babbucci M, van Hout JKJ, Maes G, Bargelloni L, Nielsen RO, Taylor MI, Carvalho GR, FishPopTrace Consortium, Panitz F. (2012) SNP discovery using next generation transcriptomic sequencing in Atlantic Herring (Clupea harengus). PLoS ONE 7: e42089

Higgins RM, Danilowicz BS, Balbuena JA, Daníelsdóttir AK, Geffen AJ, Meijer WG, Modin J, Montero FE, Pampoulie C, Perdiguero D, Schreiber A, Stéfansson MÖ, Wilson B (2010) Multi-disciplinary fingerprints reveal the harvest location of cod (Gadus morhua) in the Northeast Atlantic. Mar Ecol Prog Ser 404:197-206

Holst JC, Slotte A (1998) Effects of juvenile nursery on geographic spawning distribution in Norwegian spring spawning herring (Clupea harengus L.). ICES J Mar Sci 55:987996

Huse G, Railsback SF, Fernø A (2002) Modelling changes in the migration pattern of herring: collective behaviour and numerical domination. J Fish Biol 60:571-582 
Huse G, Railsback SF, Fernø A (2002) Modelling changes in the migration pattern of herring: collective behaviour and numerical domination. J Fish Biol 60:571-582.

Husebo A, Slotte A, Clausen LAW, Mosegaard H (2005) Mixing of populations or year class twinning in Norwegian spring spawning herring? Mar Fresh Res 56:763-772

Hutchinson WF (2008) The dangers of ignoring stock complexity in fishery management: the case of the North Sea cod. Biol Lett 4:693-695

ICES (2012) Report of the Working Group on Widely Distributed Stocks (WGWIDE), 21-27 August 2012, Lowestoft, United-Kingdom. ICES CM 2012/ACOM:16

Jakobsson J (1980) Exploitation of the Icelandic spring- and summer-spawning herring in relation to fisheries management. Rapports et Procès Verbaux des Réunions du Conseil International pour L'Exploration de la Mer 177:23-42

Jakobsson J, Vilhjlmsson H, Schopka SA (1969) On the biology of the Icelandic herring stock. Rit Fiskideildar 4:1-18

Johannessen A, Nottestad L, Fernö A, Langard L, Skaret G (2009) Two components of Northeast Atlantic herring within the same school during spawning: support for the existence of a metapopulaion? ICES J Mar Sci 66:1740-1748

Jung K-M, Folkvord A, Kjesbu OS, Agnalt A, Thorsen A, Sundby S (2012) Egg buoyancy variability in local populations of Atlantic cod (Gadus morhua). Mar Biol 159:19691980

Jørgensen HBH, Hansen MM, Bekkevold D, Ruzzante DE, Loeschcke V (2005) Marine landscapes and population genetic structure of herring (Clupea harengus L.) in the Baltic Sea. Mol Ecol 14:3219-3234

Lamichhaney S, Barrio AM, Rafati N, Sundström G, Rubin C-J, Gilbert ER, Berglund J, Wetterbom A, Laikre L, Webster MT, Grabherr M, Ryman N, Andersson L (2012) Population-scale sequencing reveals genetic differentiation due to local adaptation in Atlantic herring. Proc Natl Acad Sci USA 109:19345-19350

Langgård L (2013) Metapopulation dynamics in Atlantic herring (Clupea harengus L.) in a small semi-enclosed coastal marine ecosystem. $\mathrm{PhD}$ in Fisheries Biology. University of Bergen.

Libungan LA, Ólafsdóttir G, Skírnisdóttir S, Pálsson S, Pampoulie C, Björnsdóttir SH, Ólafsson K, Óskarsson G, Daníelsdóttir AK (2012) Fourteen new microsatellite markers for Atlantic herring Clupea harengus. J Fish Biol 81:1422-1426

Lie U, Dahl, O, Østvedt, OJ (1978). Aspects of the life history of the local herring stock in Lindåspollene, western Norway. Fiskeridirektoratets Skrifter Serie Havundersøkelser 16:369-404

Limborg MT, Helyar SJ, de Bruyn M, Taylor MI, Nielsen EE, Ogden R, Carvalho GR, Consortium F, Bekkevold D (2012) Environmental selection on transcriptome-derived SNPs in a high gene flow marine fish, the Atlantic herring (Clupea harengus). Mol Ecol 21:3686-3703

Mariani S, Hutchinson WF, Hatfield EMC, Ruzzante DE, Simmonds EJ, Dahlgren TG, Andre C, Brigham J, Torstensen E, Carvalho GR (2005) North Sea herring population structure revealed by microsatellite analysis. Mar Ecol Prog Ser 303:245-257

McQuinn IH (1997) Metapopulations and the Atlantic herring. Rev Fish Biol Fish 7:297-329

McPherson AA, O'Reilly PT, McParland TL, Jones MW, Bentzen P (2001) Isolation of nine novel tetranucleotide microsatellites in Atlantic herring (Clupea harengus). Mol Ecol Notes 1:31-32

Montero-Pau J, Gómez A, Muñoz J (2008) Application of an inexpensive and highthroughput genomic DNA extraction method for the molecular ecology of zooplanktonic diapausing eggs. Limnol Oceanogr Methods 6:218-222 
Nielsen EE, Hansen MM, Meldrup D (2006) Evidence of microsatellite hitch-hiking selection in Atlantic cod (Gadus morhua L.): implications for inferring population in nonmodel organisms. Mol Ecol 15:3219-3229

Nielsen EE, Cariani A, Aoidh EM, MAes GE, Milano I, Ogden R, Taylor M, HemmerHansen J, Babbucci M, Bargelloni L, Bekkevold D, Diopere E, Grenfell L, Helyar S, Limborg MT, Martinsohn JT, McEwing R, Panitz F, Patarnello T, Tinti F, Van Houdt JKJ, Volckaert FAM, Waples RS, FishPop Trace consortium, Carvlho GR (2012) Geneassociated markers provide tools for tackling illegal fishing and false eco-certification. Nat Commun 3:851

O'Connel M, Dillon MC, Wright JM (1998) Development of primers for polymorphic microsatellite loci in the Pacific herring (Clupea harengus pallasi). Mol Ecol 7:358360

Olsen JB, Lewis CJ, Kretschmer EJ, Wilson SL, Seeb JE (2002) Characterization of 14 tetranucleotide microsatellite loci derived from Pacific herring. Mol Ecol Notes 2:101103

Overholtz WJ (2002) The Gulf of Maine-Georges Bank Atlantic herring (Clupea harengus): spatial pattern analysis of the collapse and recovery of a large marine fish complex. Fish Res 57:237-254

Óskarsson GJ, Gudmundsdottir A, Sigurdsson T (2009) Variation in spatial distribution and migration of Icelandic summer-spawning herring. ICES J Mar Sci 66:1762-1767

Ólafsson K, Hjörleifsdóttir S, Pampoulie C, Hreggviðsson GÓ, Guðjónsson S (2010) Novel set of multiplex assays (SalPrint15) for efficient analysis of 15 microsatellite loci of contemporary samples of the Atlantic salmon (Salmo salar). Mol Ecol Res 10:533-537

Pampoulie C, Daníelsdóttir AK, Thorsteinsson V, Hjörleifsson E, Marteinsdóttir G, Ruzzante DE (2012) The composition of adult overwintering and juvenile aggregations of Atlantic cod (Gadus morhua L.) around Iceland using neutral and functional markers: a statistical challenge. Can J Fish Aquat Sci 69:307-320

Pritchard JK, Stephens M, Donnelly P (2000) Inference of population structure using multilocus genotype data. Genetics 155:945-959

Reiss H, Hoarau G, Dickey-Collas M, Wolff WJ (2009) Genetic structure of marine fish: mismatch between biological and fisheries management units. Fish Fish 10:361-395

Ricklefs RE, Wikelski M (2002) The physiology/life history nexus. Trends Ecol Evol 17:462468

Rosenberg NA (2004) Distruct: a program for the graphical display of population structure. Mol Ecol Notes 4:137-138

Rousset F (2008) Genepop'007: a complete re-implementation of the genepop software for Windows and Linux. Mol Ecol Res 8:103-106

Runnstrom S (1941) Racial analysis of the herring in Norwegian waters. Fiskdir Skr Ser Havunders 6:5-10

Ruzzante DE (1998) A comparison of several measures of genetic distance and population structure with microsatellite data: bias and sampling variance. Can J Fish Aquat Sci 55:1-14

Ruzzante DE, Mariani S, Bekkevold D, André C, Mosegaard H, Clausen LAW, Dahlgren TG, Hutchinson WF, Hatfield EMC, Torstensen E, Brigham J, Simmonds EJ, Laikre L, Larsson LC, Stet RJM, Ryman N, Carvalho GR (2006) Biocomplexity in a highly migratory pelagic marine fish, Atlantic herring. Proc Roy Soc London B Biol Sci 273:1459-1464

Ryman N, Palm S (2006) POWSIM: a computer program for assessing statistical power when testing for genetic differentiation. Mol Ecol 6:600-602 
Shaw PW, Turan C, Wright JM, O'Connel M, Carvalho GR (1999) Microsatellite DNA analysis of population structure in Atlantic herring (Clupea harengus), with direct comparison to allozyme and mtDNA RLFP analyses. Heredity 83:490-499

Silva FFG, Slotte A, Johannessen A, Kennedy J, Kjesbu OS (2013) Strategies for partition between body growth and reproductive investment in migratory and stationary populations of spring-spawning Atlantic herring (Clupea harengus L.). Fish Res 138:71-79

Smith JP, Robertson SG, Horn PL, Bull B, Anderson OF, Stanton BR, Oke CS (2002) Multiple techniques for determining stock relationships between orange roughy, Hoplostethus atlanticus, fishereies in the eastern Tasman Sea. Fish Res 58:119-140

Smylie M (2004) Herring. A history of the silver darlings. Tempus, Tempus publishing, The Mill, Brimscombe Port, Gloucestershire:224pp

Sørensen, Ø. 2012. Comparative biology and population dynamics between Trondheimsfjord herring and Norwegian Spring Spawning herring-Implications for management. Master of Science in Fisheries Biology and Fisheries Management. University of Bergen, $58 \mathrm{pp}$.

Syrjänen J, Kiljunen M, Karjalainen J, Eloranta A, Muotka T (2008) Survival and growth of brown trout Salmo trutta L. embryos and the timing of hatching and emergence in two boreal lake outlet streams. J Fish Biol 72:985-1000

Tamdrari H, Brêthes JC, Castonguay M, Duplisea DE (2012a) Homing and group cohesion in Atlantic cod Gadus morhua revealed by tagging experiments. J Fish Biol 81:714-727

Tamdrari H, Castonguay M, Brêthes JC, Galbraith PS, Duplisea DE (2012b) The dispersal pattern and behaviour of Atlantic cod (Gadus morhua) in the northern Gulf of St Lawrence: results from tagging experiments. Can J Fish Aquat Sci 69:112-121

Teacher AGF, André C, Jonsson PR, Merilä J (2013) Oceanographic connectivity and environmental correlates of genetic structuring in Atlantic herring in the Baltic Sea. Evol Appl 6:549-567

Team RC (2012) R: A language and environment for statistical computing. R Foundation for Statistical Computing, Vienna, Austria. ISBN 3-900051-07-0, URL: http://Rproject.org/.

Thorsteinsson V, Pálsson ÓK, Jónsdóttir IG, Pampoulie C (2012) Consistency in the behaviour types of the Atlantic cod: repeatability, timing of migration and geolocation. Mar Ecol Prog Ser 462:251-260

Toresen R, Østvedt OJ (2000) Variation in abundance of Norwegian spring-spawning herring (Clupea harengus, Clupeidae) throughout the 20th century and the influence of climatic fluctuations. Fish Fish 1:231-256

Turan C, Carvalho GR, Mork J (1998) Molecular analysis of Atlanto-Scandian herring (Clupea harengus) populations using allozymes and mitochondrial DNA markers. J Mar Biol Assoc UK 78:269-283

Weir BS, Cockerham CC (1984) Estimating $F$-statistics for the analysis of population structure. Evolution 38:1358-1370

Whitlock RE, McAllister MK, Block BA (2012) Estimating fishing and natural mortality rates for Pacific bluefin tuna (Thunnus orientalis) using electronic tagging data. Fish Res 119-120:115-127

Wood AD, Collie JS, Kohler NE (2007) Estimating survival of the shortfin mako Isurus oxyrinchus (Rafinesque) in the north-west Atlantic from tag-recapture data. J Fish Biol 71:1679-1695 
Table 1. Sampling areas and information for 14 samples of North Atlantic herring Clupea harengus. The maturity stage of individual fish is expressed in percentage per stages.

\begin{tabular}{|c|c|c|c|c|c|c|c|c|c|c|c|c|c|c|}
\hline $\begin{array}{l}\text { Sample acronym } \\
\text { Information }\end{array}$ & FASH & FSSH & ISSH403 & ISSH411 & ISSH463 & ISSH473 & NASH & NSSH12 & NSSH10 & SCOTLAND & NLSSH & NLSSH & NLSSH & NLSSH \\
\hline Sampling area & Faroese Islands & $\begin{array}{l}\text { Faroese } \\
\text { Islands }\end{array}$ & Iceland & Iceland & Iceland & Iceland & Lofoten & Norway & Norway & Scotland & $\begin{array}{c}\text { Trondheims- } \\
\text { fjorden }\end{array}$ & $\begin{array}{l}\text { Landvik- } \\
\text { vannet }\end{array}$ & $\begin{array}{l}\text { Lindås } \\
\text { pollene }\end{array}$ & $\begin{array}{l}\text { Luster- } \\
\text { fjorden }\end{array}$ \\
\hline Stock acronym & FASH & FSSH & ISSH & ISSH & ISSH & ISSH & NASH & NSSH & NSSH & NASH.S & NLSSH & NLSSH & NLSSH & NLSSH \\
\hline Sample code & 1 & 2 & 3 & 4 & 5 & 6 & 7 & 8 & 9 & 10 & 11 & 12 & 13 & 14 \\
\hline \multicolumn{15}{|l|}{ Maturity stage*: } \\
\hline \multirow[t]{3}{*}{ Maturing (3-5) } & $5(5)$ & $95(5)$ & $2(3)$ & $99(5)$ & $1(4)$ & $15(4)$ & & $52(4)$ & $13(4)$ & & na & $1(4)$ & $13(4)$ & $77(4)$ \\
\hline & & & $17(4)$ & & $9(5)$ & $60(5)$ & & $30(5)$ & $84(5)$ & & & $62(5)$ & $44(5)$ & $5(5)$ \\
\hline & & & $81(5)$ & & & & & & & & & & & \\
\hline Spawning (6) & & 5 & & & 90 & 10 & 1 & 18 & 2 & 100 & & 36 & 42 & \\
\hline Recently spawned (7) & & & & 1 & & & 57 & & 1 & & & 1 & 2 & \\
\hline Resting (8) & 95 & & & & & 5 & 33 & & & & & & & \\
\hline Date & 27.11.2009 & 28.3.2011 & 5.7.2009 & 9.7.2009 & 2.7.2010 & 5.7 .2010 & 11.8.2010 & 29.1.2012 & 14.2 .2010 & 9.1 .2010 & 3.12 .2010 & 12.5 .2010 & 3.2010 & 8.11 .2011 \\
\hline \multirow[t]{2}{*}{ Coordinates } & $60^{\circ} 48.00^{\prime} \mathrm{N}$ & $62^{\circ} 06.06^{\prime} \mathrm{N}$ & $64^{\circ} 13.75^{\prime} \mathrm{N}$ & $63^{\circ} 44.84^{\prime} \mathrm{N}$ & $64^{\circ} 05.40^{\prime} \mathrm{N}$ & $63^{\circ} 46.10^{\prime} \mathrm{N}$ & $67^{\circ} 14.60^{\prime} \mathrm{N}$ & $63^{\circ} 17.50^{\prime} \mathrm{N}$ & $62^{\circ} 531.00^{\prime} \mathrm{N}$ & $58^{\circ} 743.80^{\prime} \mathrm{N}$ & $63^{\circ} 42.00^{\prime} \mathrm{N}$ & $58^{\circ} 19.20^{\prime} \mathrm{N}$ & $60^{\circ} 43.80^{\prime} \mathrm{N}$ & $61^{\circ} 47.67^{\prime} \mathrm{N}$ \\
\hline & $06^{\circ} 10.80^{`} \mathrm{~W}$ & $06^{\circ} 45.00^{`} \mathrm{~W}$ & $22^{\circ} 56.29^{\prime} \mathrm{W}$ & $16^{\circ} 26.80^{\prime} \mathrm{W}$ & $23^{\circ} 01.90^{\prime} \mathrm{W}$ & $16^{\circ} 19.40^{\prime} \mathrm{W}$ & $13^{\circ} 17.00^{\circ} \mathrm{E}$ & $07^{\circ} 14.70^{\prime} \mathrm{E}$ & $05^{\circ} 14.00^{\prime} \mathrm{E}$ & $05^{\circ} 22.20^{\prime} \mathrm{W}$ & $11^{\circ} 00.00^{\circ} \mathrm{E}$ & $08^{\circ} 30.10^{\prime} \mathrm{E}$ & $05^{\circ} 08.00^{\prime} \mathrm{E}$ & $07^{\circ} 57.33^{\prime} \mathrm{E}$ \\
\hline Sample size & 119 & 40 & 48 & 84 & 70 & 93 & 88 & 87 & 63 & 105 & 120 & 149 & 64 & 128 \\
\hline Age range & $4-11$ & $5-10$ & $4-13$ & $2-11$ & $4-14$ & $2-11$ & $3-12$ & $3-13$ & $4-15$ & $3-12$ & $3-15$ & $2-10$ & NA & $2-6$ \\
\hline \multicolumn{15}{|l|}{ Length (mm): } \\
\hline mean & 373 & 333 & 325 & 326 & 329 & 308 & 338 & 329 & 324 & 296 & 272 & 276 & 325 & 181 \\
\hline $\mathrm{SD}$ & 13 & 11 & 23 & 22 & 19 & 36 & 17 & 15 & 15 & 15 & 12 & 17 & 14 & 14 \\
\hline Range & $318-396$ & $310-350$ & $280-360$ & $260-360$ & $280-370$ & $190-360$ & $280-370$ & $295-360$ & $295-360$ & $267-337$ & $230-305$ & $225-320$ & $295-360$ & $145-225$ \\
\hline
\end{tabular}

* numbers between brackets indicates the specific stage in which fish were. na, non available data. 
Fig. 1. Current migration pattern of the adult part of the Norwegian spring-spawning herring

(NSSH) and interactions with other surrounding stocks, i.e. Icelandic summer-spawning herring (ISSH), Faroese autumn-spawning herring (FASH), and Norwegian autumn-spawning herring (NASH).

Fig. 2. Sampling locations of Atlantic herring C. harengus in Norwegian Sea and surrounding waters. See Table 1 for sample codes.

709

Fig. 3. Multi-dimensional scaling plot of Atlantic herring C. harengus in Norwegian Sea and surrounding waters: a) all loci included, b) without the outlier Cpa111. See Table 1 for sample codes.

Fig. 4. Hierarchical Bayesian cluster analysis performed in STRUCTURE using all loci and all samples. A total of 10 runs were performed for each $K$, from $K=1$ to 10 with 350,000

716 Burn-in, 500,000 MCMC, using an admixture model with correlated allele frequencies and no prior information on sample location. (a) Represents the first hierarchical level including all samples. Two clusters were detected, the first one composed of composed of all Northeast Atlantic samples, and the second of the fjord samples (NLSSH), (b) represents the second

720 hierarchical level only including the NLSSH samples. Two clusters were detected, the first 721 one composed of composed of sample 12, and the second of samples 11, 13 and 14. See Table 7221 for sample codes. 
724 Fig. 5. Bayesian cluster analysis performed in STRUCTURE using neutral loci and all herring 725 samples. A total of 10 runs were performed for each $K$, from $K=1$ to 10 with 350,000 Burn726 in, 500,000 MCMC, using an admixture model with correlated allele frequencies and no prior

727 information on sample location. Additional hierarchical analyses did not detect any additional 728 clusters within the two main groups, i.e. the Northeast Atlantic samples and the fjords 729 samples (NLSSH). See Table 1 for sample codes.

730

731 Fig. 6. Allele frequencies at Cpa111 locus. All samples of North Atlantic populations were 732 combined while allele frequencies of the four Norwegian local-spawning herring are depicted 733 separately. NA, North Atlantic population; See Table 1 for sample codes. 


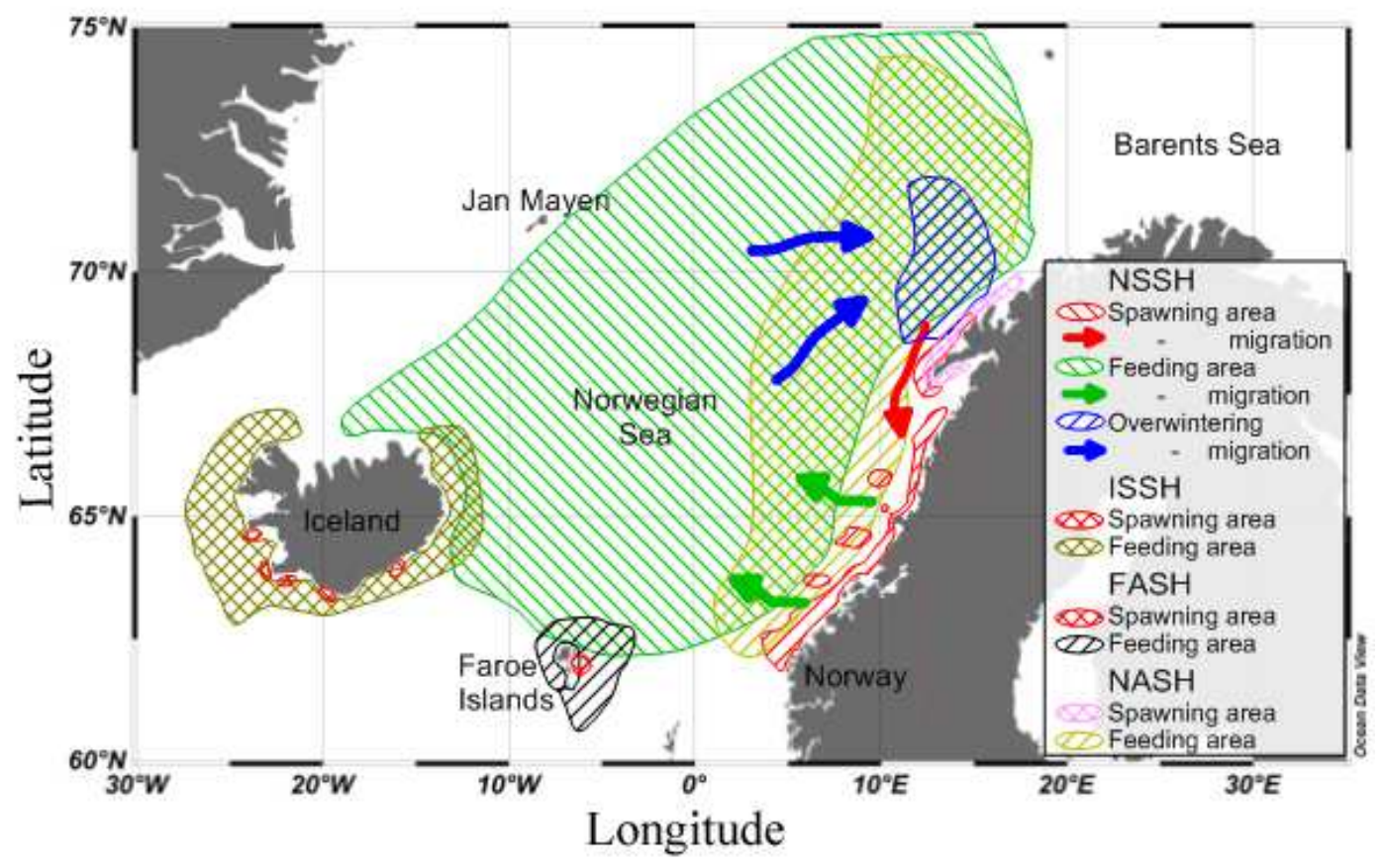

736

737

738

739

Fig. 1. 


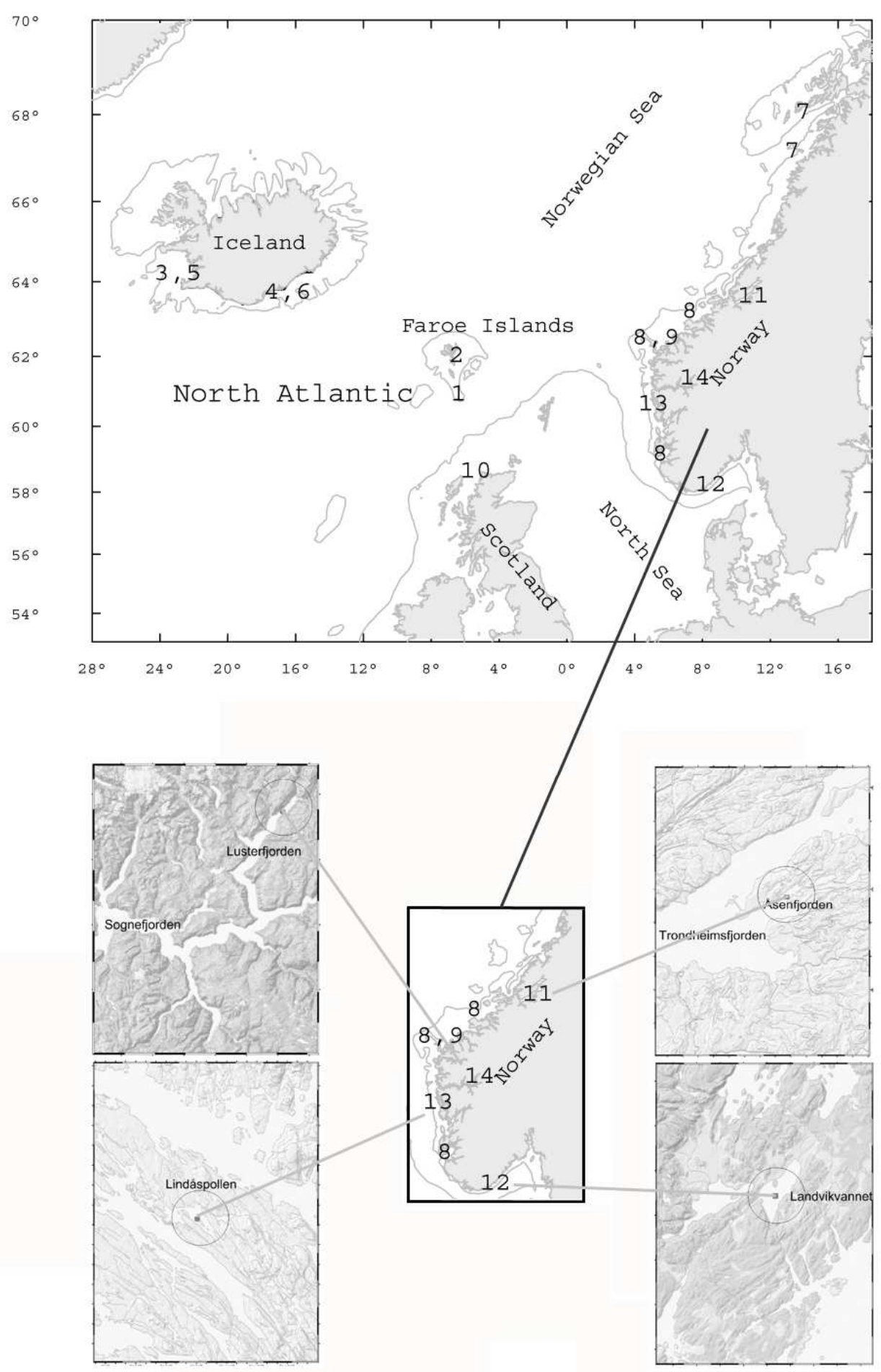

Fig. 2. 


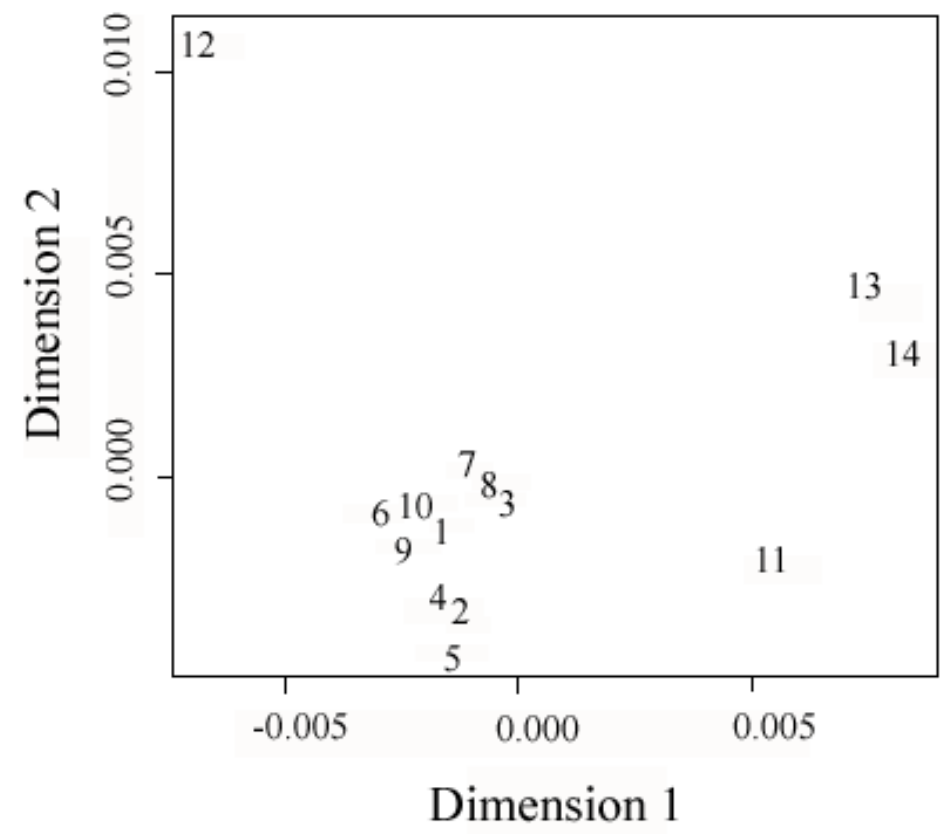

743

744 Fig. 3a.

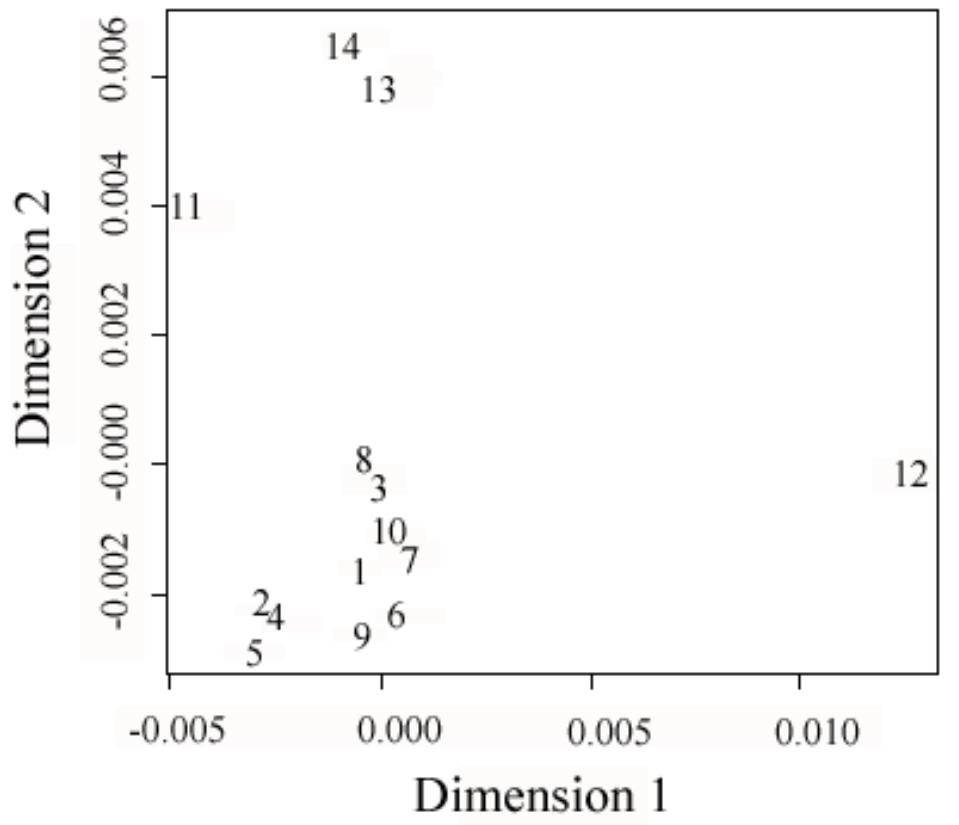

745

746 Fig. 3b. 
(a)

Population 1

Population 2

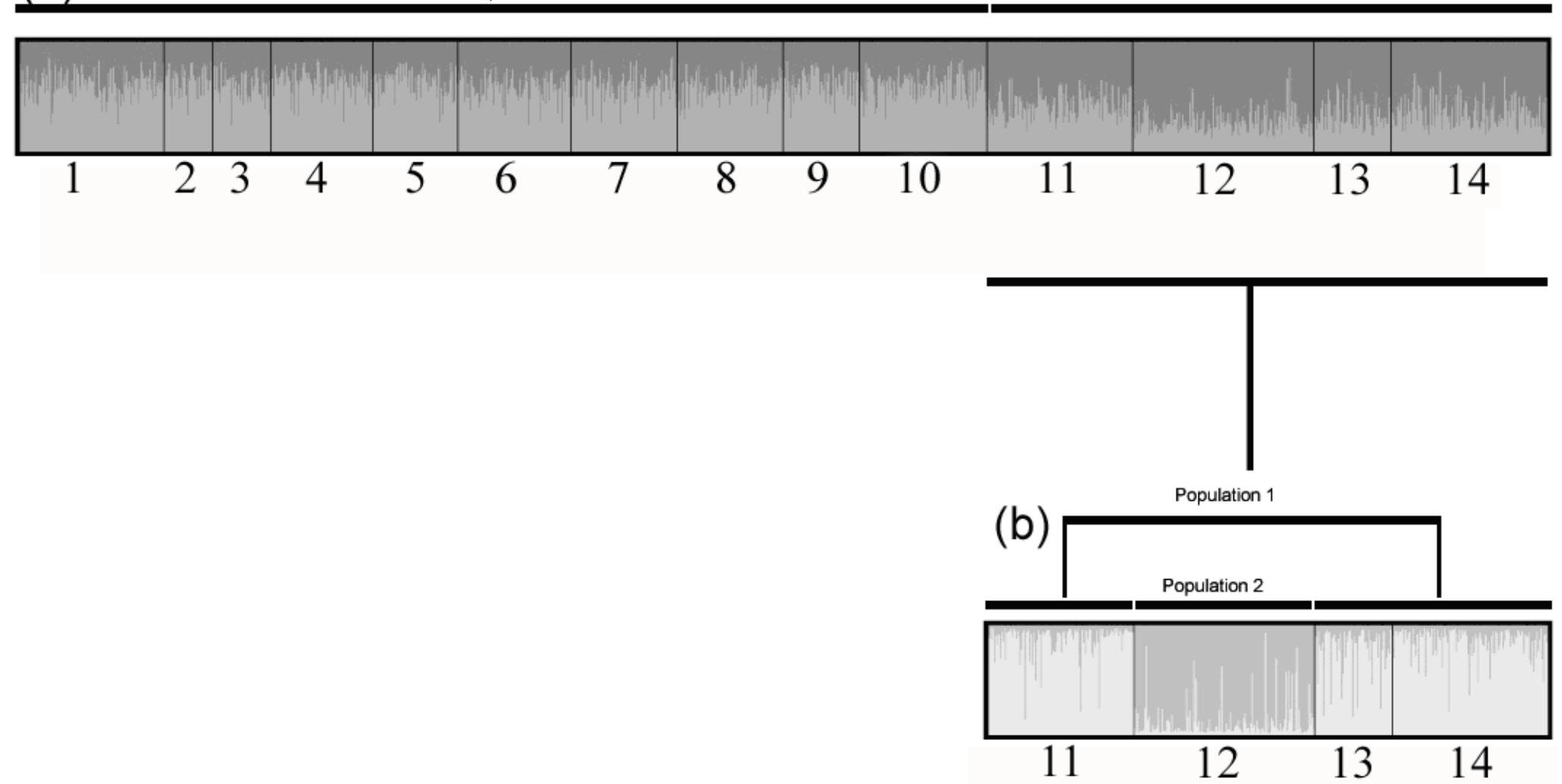

Fig. 4. 


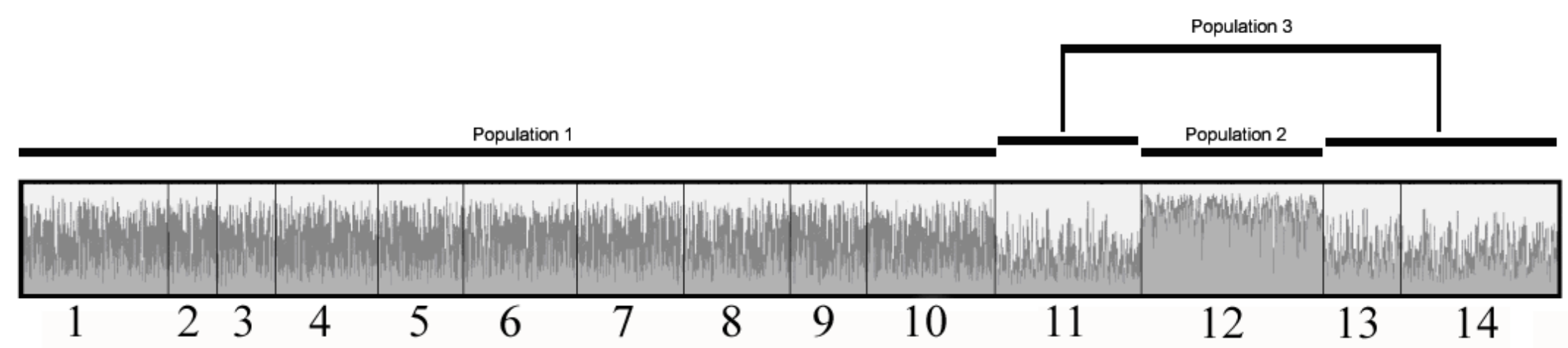

Fig. 5. 


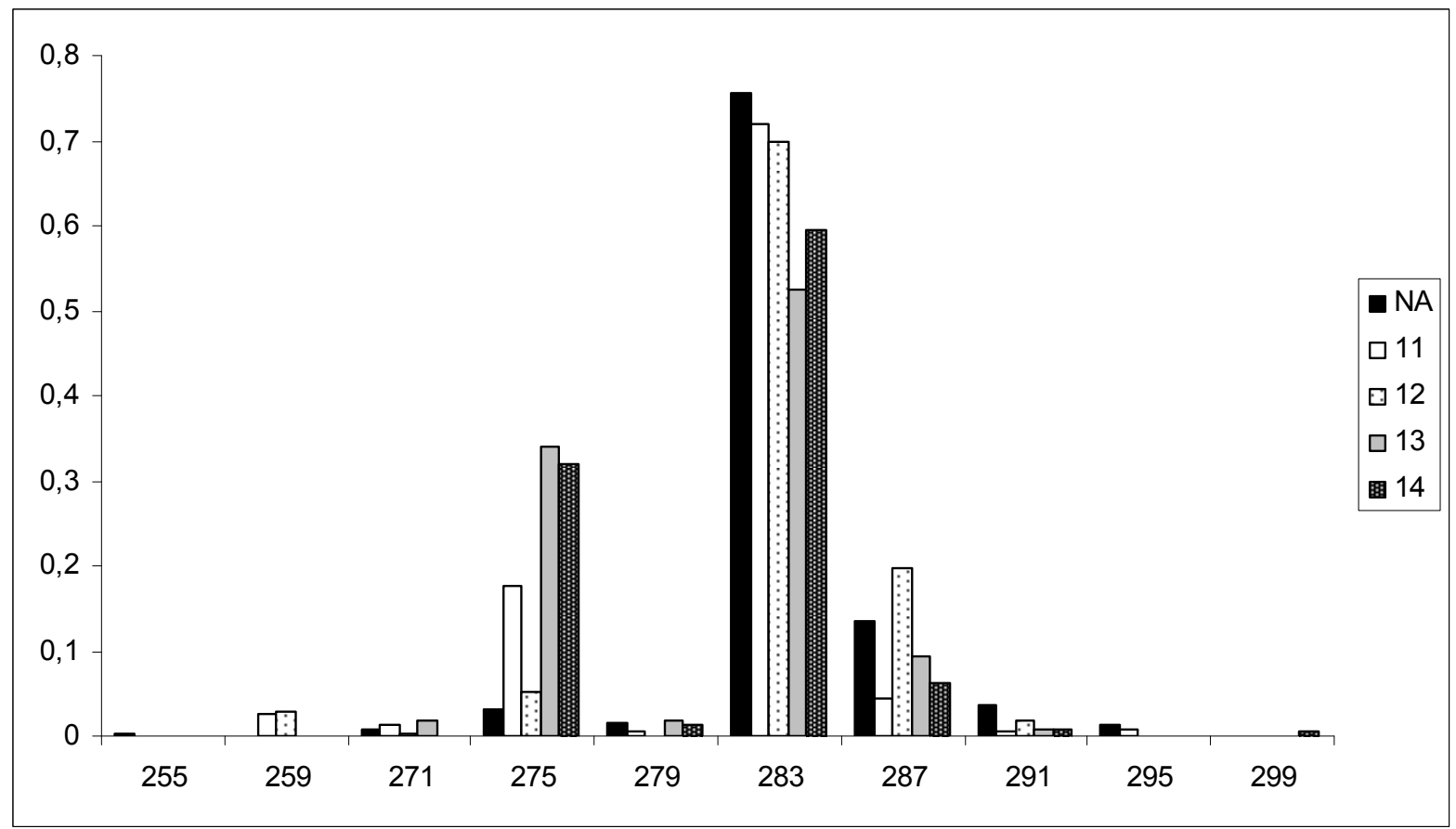

Fig. 6. 
Supplementary Table S1: Characteristics of multiplexes for 24 microsatellite loci of Atlantic herring $\boldsymbol{C}$. harengus. $T m$ stands for annealing temperature and $\mu l$ for micro-litres of primer used. Genotyping quality reports the percentage of individuals which were correctly genotyped at a specific microsatellite loci.

\begin{tabular}{llllccc}
\hline Multiplex & Loci & $\mu 1$ & Tm & Dye & Allele range & Genotyping quality \\
\hline SildPrint2 & Cha113 & 0.10 & 58 & PET & $104-156$ & 97 \\
& Cha17 & 0.18 & 58 & 6FAM & $85-189$ & 99 \\
& Cha1059 & 0.03 & 58 & NED & $63-127$ & 98 \\
& Cha1020 & 0.14 & 58 & VIC & $153-245$ & 90 \\
& Cpa111 & 0.16 & 58 & VIC & $256-295$ & 91 \\
SildPrint4 & Cpa113 & 0.06 & 57 & PET & $118-230$ & 93 \\
& Cha1017 & 0.15 & 57 & VIC & $161-213$ & 98 \\
& Cpa103 & 0.13 & 57 & 6FAM & $163-263$ & 93 \\
& Cpa112 & 0.14 & 57 & VIC & $232-416$ & 92 \\
& Cpa108 & 0.10 & 57 & NED & $233-275$ & 96 \\
SildPrint66 & msild12 & 0.03 & 58 & VIC & $73-139$ & 97 \\
& Cha1027 & 0.10 & 58 & PET & $113-213$ & 100 \\
& Cha63 & 0.10 & 58 & NED & $137-181$ & 100 \\
& Cpa101 & 0.06 & 58 & VIC & $169-321$ & 98 \\
SildPrint7 & Cpa104 & 0.08 & 60 & NED & $180-506$ & 98 \\
& Cpa114 & 0.08 & 60 & VIC & $178-282$ & 100 \\
& Cha1202 & 0.10 & 60 & 6FAM & $97-173$ & 99 \\
SildPrint9 & Cha4 & 0.07 & 58 & VIC & $106-194$ & 99 \\
& Cpa102 & 0.06 & 58 & NED & $128-420$ & 99 \\
& msild13 & 0.16 & 58 & 6FAM & $176-251$ & 96 \\
SildPrint13 & msild17 & 0.10 & 58 & VIC & $336-420$ & 99 \\
& msild24 & 0.15 & 58 & PET & $165-351$ & 99 \\
& msild27 & 0.06 & 58 & 6FAM & $185-233$ & 56 \\
& msild32 & 0.10 & 58 & VIC & $172-272$ & \\
\hline
\end{tabular}


Supplementary Table S2: Genetic diversity of the $\mathbf{2 4}$ microsatellite loci. Expected heterozygosity $\left(H_{\mathrm{e}}\right)$ and deviation from HWE $\left(F_{\mathrm{IS}}\right)$ for 24 microsatellite loci in 14 samples of Atlantic herring C. harengus. See Table 1 for sample codes.

\begin{tabular}{|c|c|c|c|c|c|c|c|c|c|c|c|c|c|c|c|c|c|c|c|c|c|c|c|c|c|c|c|c|}
\hline $\begin{array}{l}\text { Sample } \\
\end{array}$ & & & & & & & & & & & & & & & & & & & & & & & & & & & & \\
\hline Locus & $H_{\mathrm{e}}$ & $F_{1 \mathrm{~s}}$ & $H_{\mathrm{e}}$ & $F_{\text {is }}$ & $H_{c}$ & $F_{\text {is }}$ & $H_{\mathrm{c}}$ & $F_{F i s}$ & $H_{\mathrm{c}}$ & $F_{\mathrm{is}}$ & $H_{\mathrm{e}}$ & $\overline{F_{\mathrm{is}}}$ & $H_{\mathrm{c}}$ & $F_{\text {is }}$ & $H_{\mathrm{e}}$ & $F_{i \mathrm{~s}}$ & $H_{\mathrm{e}}$ & $F_{1 \mathrm{~s}}$ & $H_{\mathrm{e}}$ & $F_{15}$ & $H_{\mathrm{c}}$ & $F_{1 \mathrm{~s}}$ & $H_{\mathrm{e}}$ & $F_{1 \mathrm{~s}}$ & $H_{\mathrm{c}}$ & $F_{1 \mathrm{~s}}$ & $H_{\mathrm{e}}$ & $F_{1 \mathrm{~s}}$ \\
\hline Cha4 & 0.874 & 0.091 & 0.884 & -0.031 & 0.862 & 0.098 & 0.856 & 0.037 & 0.889 & 0.076 & 0.875 & -0.025 & 0.853 & 0.020 & 0.858 & 0.020 & 0.865 & 0.058 & 0.868 & 0.074 & 0.884 & 0.034 & 0.852 & 0.012 & 0.854 & 0.060 & 0.882 & 0.020 \\
\hline Cha17 & 0.941 & 0.025 & 0.937 & 0.002 & 0.929 & 0.025 & 0.944 & 0.010 & 0.941 & 0.023 & 0.944 & 0.026 & 0.943 & 0.019 & 0.949 & $0.036^{*}$ & 0.945 & 0.024 & 0.941 & 0.015 & 0.942 & 0.006 & 0.928 & 0.007 & 0.941 & -0.055 & 0.940 & 0.025 \\
\hline Cha63 & 0.862 & 0.010 & 0.878 & 0.136 & 0.862 & 0.019 & 0.868 & 0.005 & 0.860 & -0.054 & 0.858 & 0.005 & 0.851 & 0.044 & 0.855 & -0.060 & 0.847 & -0.024 & 0.841 & 0.014 & 0.846 & 0.021 & 0.816 & -0.083 & 0.859 & -0.022 & 0.863 & 0.053 \\
\hline Chal13 & 0.891 & -0.003 & 0.875 & 0.016 & 0.893 & 0.026 & 0.884 & -0.017 & 0.883 & 0.039 & 0.872 & -0.005 & 0.877 & 0.091 & 0.866 & -0.036 & 0.863 & -0.003 & 0.889 & 0.010 & 0.881 & 0.036 & 0.861 & 0.023 & 0.905 & 0.010 & 0.881 & -0.014 \\
\hline Cha1017 & 0.793 & 0.018 & 0.788 & 0.054 & 0.839 & 0.066 & 0.834 & 0.095 & 0.843 & 0.051 & 0.798 & 0.134 & 0.825 & 0.008 & 0.797 & 0.098 & 0.833 & 0.124 & 0.815 & 0.047 & 0.802 & 0.050 & 0.778 & -0.015 & 0.762 & 0.084 & 0.812 & 0.035 \\
\hline Cha 1020 & 0.926 & 0.008 & 0.931 & -0.003 & 0.920 & -0.004 & 0.918 & -0.042 & 0.923 & 0.028 & 0.923 & -0.017 & 0.914 & 0.026 & 0.915 & 0.013 & 0.921 & 0.004 & 0.920 & 0.036 & 0.917 & -0.036 & 0.881 & -0.055 & 0.871 & -0.073 & 0.901 & $\begin{array}{l}-0.044 \\
\end{array}$ \\
\hline Cha 1027 & 0.934 & -0.012 & 0.923 & 0.096 & 0.907 & -0.022 & 0.936 & 0.052 & 0.923 & 0.032 & 0.930 & 0.058 & 0.939 & -0.023 & 0.938 & 0.139 & 0.929 & -0.022 & 0.930 & 0.061 & 0.922 & 0.028 & 0.917 & 0.023 & 0.908 & 0.033 & 0.914 & 0.008 \\
\hline Cha1059 & 0.670 & 0.035 & 0.695 & 0.257 & 0.708 & 0.132 & 0.674 & 0.065 & 0.666 & 0.020 & 0.663 & 0.061 & 0.660 & $0.130^{*}$ & 0.679 & 0.059 & 0.663 & -0.043 & 0.729 & 0.091 & 0.693 & 0.123 & 0.668 & 0.035 & 0.787 & 0.080 & 0.680 & 0.143 \\
\hline Cha 1202 & 0.701 & 0.057 & 0.744 & 0.082 & 0.676 & -0.007 & 0.709 & -0.048 & 0.763 & -0.056 & 0.722 & 0.023 & 0.750 & 0.060 & 0.761 & 0.097 & 0.761 & 0.009 & 0.750 & -0.085 & 0.753 & 0.002 & 0.704 & -0.008 & 0.760 & 0.027 & 0.752 & 0.065 \\
\hline Cpa101 & 0.919 & 0.000 & 0.916 & 0.006 & 0.909 & 0.033 & 0.915 & 0.047 & 0.910 & 0.119 & 0.915 & 0.028 & 0.913 & -0.039 & 0.914 & -0.036 & 0.912 & 0.044 & 0.926 & -0.006 & 0.918 & -0.011 & 0.900 & 0.054 & 0.912 & 0.040 & 0.916 & 0.032 \\
\hline Cpa102 & 0.923 & -0.024 & 0.927 & -0.038 & 0.912 & 0.034 & 0.929 & -0.031 & 0.922 & 0.050 & 0.924 & 0.028 & 0.927 & 0.062 & 0.928 & -0.001 & 0.923 & 0.048 & 0.930 & 0.002 & 0.939 & -0.007 & 0.913 & -0.003 & 0.913 & -0.053 & 0.919 & 0.060 \\
\hline Cpa103 & 0.874 & 0.045 & 0.880 & 0.162 & 0.878 & 0.085 & 0.891 & 0.086 & 0.878 & 0.034 & 0.885 & 0.130 & 0.884 & 0.025 & 0.883 & 0.096 & 0.870 & 0.047 & 0.874 & 0.144 & 0.874 & -0.018 & 0.884 & 0.077 & 0.865 & 0.039 & 0.839 & 0.045 \\
\hline Cpa 104 & 0.836 & 0.022 & 0.840 & 0.120 & 0.823 & 0.049 & 0.870 & 0.041 & 0.834 & 0.073 & 0.878 & 0.040 & 0.823 & 0.155 & 0.810 & 0.0182 & 0.847 & 0.101 & 0.832 & 0.024 & 0.739 & 0.071 & 0.830 & 0.067 & 0.719 & -0.023 & 0.699 & 0.057 \\
\hline Cpa 108 & 0.481 & 0.070 & 0.535 & 0.103 & 0.492 & 0.121 & 0.540 & 0.135 & 0.447 & 0.024 & 0.461 & -0.043 & 0.424 & -0.093 & 0.543 & 0.072 & 0.448 & 0.059 & 0.457 & 0.025 & 0.627 & -0.018 & 0.396 & -0.083 & 0.533 & 0.020 & 0.576 & 0.082 \\
\hline Cpa111 & 0.434 & -0.003 & 0.389 & -0.028 & 0.331 & 0.003 & 0.372 & -0.001 & 0.397 & 0.021 & 0.402 & 0.033 & 0.502 & 0.009 & 0.464 & 0.0138 & 0.402 & 0.140 & 0.349 & 0.041 & 0.447 & -0.085 & 0.468 & -0.010 & 0.600 & 0.019 & 0.541 & -0.065 \\
\hline Cpa1 12 & 0.904 & -0.027 & 0.882 & 0.066 & 0.879 & -0.078 & 0.889 & 0.003 & 0.886 & 0.033 & 0.887 & -0.020 & 0.860 & 0.038 & 0.904 & -0.092 & 0.878 & 0.085 & 0.885 & -0.017 & 0.901 & -0.019 & 0.791 & -0.065 & 0.872 & -0.050 & 0.880 & -0.017 \\
\hline Cpa113 & 0.937 & 0.030 & 0.921 & -0.044 & 0.919 & -0.025 & 0.935 & -0.025 & 0.925 & 0.035 & 0.929 & 0.016 & 0.928 & 0.010 & 0.919 & 0.035 & 0.926 & 0.030 & 0.929 & 0.011 & 0.935 & 0.010 & 0.886 & 0.022 & 0.930 & 0.035 & 0.924 & -0.020 \\
\hline Cpa114 & 0.917 & 0.043 & 0.903 & -0.038 & 0.902 & 0.087 & 0.905 & 0.049 & 0.905 & 0.111 & 0.908 & 0.013 & 0.913 & 0.089 & 0.918 & 0.038 & 0.910 & -0.013 & 0.905 & 0.016 & 0.912 & -0.010 & 0.908 & 0.044 & 0.903 & 0.048 & 0.909 & 0.008 \\
\hline msild12 & 0.883 & 0.042 & 0.849 & -0.075 & 0.892 & 0.036 & 0.873 & -0.040 & 0.874 & 0.004 & 0.877 & 0.016 & 0.876 & -0.007 & 0.893 & -0.032 & 0.883 & 0.011 & 0.881 & 0.005 & 0.881 & 0.086 & 0.860 & 0.044 & 0.873 & 0.015 & 0.879 & 0.025 \\
\hline msild13 & 0.898 & 0.012 & 0.898 & 0.011 & 0.899 & 0.014 & 0.884 & -0.004 & 0.898 & -0.026 & 0.901 & -0.057 & 0.894 & 0.005 & 0.881 & 0.051 & 0.907 & 0.021 & 0.895 & 0.028 & 0.865 & 0.003 & 0.845 & -0.006 & 0.838 & -0.003 & 0.851 & 0.012 \\
\hline msild17 & 0.895 & 0.055 & 0.898 & 0.042 & 0.881 & -0.045 & 0.887 & 0.024 & 0.884 & 0.030 & 0.888 & 0.056 & 0.878 & 0.002 & 0.878 & 0.023 & 0.894 & 0.057 & 0.896 & 0.058 & 0.857 & -0.034 & 0.811 & 0.005 & 0.847 & 0.123 & 0.821 & -0.029 \\
\hline msild24 & 0.957 & 0.023 & 0.943 & -0.021 & 0.943 & 0.039 & 0.956 & 0.053 & 0.951 & 0.062 & 0.951 & 0.034 & 0.953 & 0.041 & 0.955 & -0.006 & 0.951 & -0.016 & 0.961 & 0.004 & 0.949 & -0.014 & 0.925 & -0.018 & 0.945 & -0.048 & 0.952 & 0.030 \\
\hline msild27 & 0.816 & 0.013 & 0.790 & 0.007 & 0.811 & 0.040 & 0.786 & 0.033 & 0.791 & -0.015 & 0.823 & 0.054 & 0.801 & -0.013 & 0.787 & -0.039 & 0.753 & 0.020 & 0.806 & 0.032 & 0.816 & 0.067 & 0.782 & -0.015 & 0.808 & 0.010 & 0.811 & 0.004 \\
\hline msild32 & 0.910 & -0.028 & 0.899 & 0.178 & 0.904 & -0.025 & 0.905 & 0.047 & 0.891 & 0.022 & 0.907 & -0.026 & 0.902 & -0.053 & 0.904 & 0.056 & 0.903 & 0.041 & 0.908 & 0.061 & 0.893 & -0.020 & 0.897 & 0.040 & 0.890 & -0.037 & 0.913 & -0.028 \\
\hline$\overline{\text { Overal all loci }}$ & 0.844 & 0.020 & 0.850 & 0.042 & 0.841 & 0.028 & 0.845 & 0.022 & 0.843 & 0.032 & 0.843 & 0.024 & 0.841 & $0.025^{*}$ & 0.847 & 0.031 & 0.842 & 0.032 & 0.842 & 0.028 & 0.845 & 0.012 & 0.813 & 0.007 & 0.838 & $\begin{array}{l}0.010 \\
\end{array}$ & 0.836 & 0.019 \\
\hline
\end{tabular}

Values in bold indicate significant deviations from HWE (Exact tests, $\mathrm{p}<0.05$ ).

"Values remaining significant after Bonferroni correction $(\alpha=0.05 / 168=0.0003)$. 
Supplementary Table S3: Results from Lositan outlier tests for the $\mathbf{2 4}$ microsatellite loci in 14 samples of Atlantic herring $\boldsymbol{C}$. harengus. Expected heterozygosity $\left(H_{\mathrm{E}}\right)$ and $F_{\mathrm{ST}}$ are given. The loci in bold were identified as $95 \%$ outliers, while those marked with asterix were identified as significant outliers at a false discovery rate of 0.01 .

\begin{tabular}{lccc}
\hline Locus & Heterozygosity & $F_{\text {ST }}$ & P(Simul $F_{\text {ST }}<$ Sample $\left.F_{\text {ST }}\right)$ \\
\hline Cha4 & 0.881 & 0.008 & 0.824 \\
Cha17 & 0.948 & 0.002 & 0.113 \\
Cha63 & 0.863 & 0.003 & 0.344 \\
Cha113 & 0.889 & 0.003 & 0.358 \\
Cha1017 & 0.816 & 0.003 & 0.389 \\
Cha1020 & 0.927 & 0.008 & 0.882 \\
Cha1027 & 0.935 & 0.004 & 0.480 \\
Cha1059 & 0.695 & 0.004 & 0.471 \\
Cha1202 & 0.742 & 0.001 & 0.293 \\
Cpa101 & 0.922 & 0.002 & 0.236 \\
Cpa102 & 0.935 & 0.006 & 0.706 \\
Cpa103 & 0.885 & 0.004 & 0.483 \\
Cpa104 & 0.824 & 0.007 & 0.691 \\
Cpa108 & 0.504 & 0.005 & 0.547 \\
Cpa111* & $\mathbf{0 . 4 5 7}$ & $\mathbf{0 . 0 4 0}$ & $\mathbf{0 . 9 9 8}$ \\
Cpa112 & 0.894 & 0.011 & 0.940 \\
Cpa113 & 0.936 & 0.006 & 0.694 \\
Cpa114 & 0.916 & 0.002 & 0.209 \\
msild12 & 0.884 & 0.002 & 0.269 \\
msild13 & $\mathbf{0 . 8 9 9}$ & $\mathbf{0 . 0 1 2}$ & $\mathbf{0 . 9 8 6}$ \\
msild17 & 0.889 & 0.012 & 0.972 \\
msild24 & 0.960 & 0.003 & 0.234 \\
msild27 & 0.805 & 0.001 & 0.239 \\
msild32 & 0.910 & 0.003 & 0.298 \\
\hline
\end{tabular}


Supplementary Table S4: Outlier tests performed in BAYESCAN for the 24 microsatellite loci in 14 samples of Atlantic herring $C$. harengus. The posterior probability for the model including selection (p), the $\log 10$ of the Posterior Odds for the model including selection $(\log 10(\mathrm{PO}))$, and the estimated alpha coefficient indicating the strength and direction of selection (alpha; positive values indicate positive selection, while negative values indicate putative balancing selection) are given for each locus. It should be noted that the power to detect loci under putative balancing selection is low. The loci in bold were identified as significant outliers under a false discovery rate of 0.05 .

\begin{tabular}{|c|c|c|c|c|}
\hline Locus & $\mathrm{p}$ & $\log 10(\mathrm{PO})$ & alpha & $\overline{F_{\mathrm{ST}}}$ \\
\hline Cha4 & 1 & 1000 & -1.40 & 0.006 \\
\hline Cha17 & 1 & 1000 & -2.36 & 0.002 \\
\hline Cha63 & 1 & 1000 & -2.19 & 0.003 \\
\hline Cha113 & 1 & 1000 & -1.77 & 0.004 \\
\hline Cha1017 & 1 & 1000 & -2.46 & 0.002 \\
\hline Cha1020 & 1 & 1000 & -1.14 & 0.006 \\
\hline Cha1027 & 1 & 1000 & -1.81 & 0.004 \\
\hline Cha1059 & 1 & 1000 & -2.30 & 0.003 \\
\hline Cha1202 & 1 & 1000 & -2.04 & 0.003 \\
\hline Cpa101 & 1 & 1000 & -2.71 & 0.002 \\
\hline Cpa102 & 1 & 1000 & -1.60 & 0.005 \\
\hline Cpa103 & 1 & 1000 & -1.48 & 0.006 \\
\hline Cpa104 & 1 & 1000 & -2.03 & 0.003 \\
\hline Cpa108 & 1 & 1000 & -1.65 & 0.005 \\
\hline Cpa111 & 0.046 & -1.23 & -0.007 & 0.024 \\
\hline Cpa112 & 1 & 1000 & -1.17 & 0.008 \\
\hline Cpa113 & 1 & 1000 & -1.78 & 0.004 \\
\hline Cpa114 & 1 & 1000 & -2.38 & 0.002 \\
\hline msild12 & 1 & 1000 & -2.60 & 0.002 \\
\hline msild13 & 1 & 1000 & -1.11 & 0.009 \\
\hline msild17 & 1 & 1000 & -0.96 & 0.010 \\
\hline msild24 & 1 & 1000 & -2.23 & 0.003 \\
\hline msild27 & 1 & 1000 & -2.31 & 0.003 \\
\hline msild 32 & 1 & 1000 & -2.35 & 0.003 \\
\hline
\end{tabular}


Supplementary Table S5: Power of the 24 microsatellite loci in 10 samples of Atlantic herring $\boldsymbol{C}$. harengus. The Norwegian local spring-spawning herring were excluded from the analysis. Estimate of the resolution power of the microsatellite loci were performed using POWSIM (Ryman \& Palm 2006).

\begin{tabular}{c|cccccc}
\hline Expected $\mathrm{F}_{\mathrm{ST}}$ & Average $\mathrm{F}_{\mathrm{ST}}$ & $\chi^{2}$-test & Fisher's test & $\mathrm{N}_{\mathrm{e}}$ & Generation $(\mathrm{t})$ & Runs \\
\hline 0.0000 & 0.0000 & 0.077 & 0.075 & 1,000 & 0 & 1,000 \\
0.0000 & 0.0000 & 0.089 & 0.076 & 5,000 & 0 & 1,000 \\
0.0010 & 0.0010 & 1.000 & 1.000 & 500 & 1 & 1,000 \\
0.0010 & 0.0010 & 1.000 & 1.000 & 1,000 & 2 & 1,000 \\
0.0010 & 0.0010 & 1.000 & 1.000 & 5,000 & 10 & 1,000 \\
0.0025 & 0.0025 & 1.000 & 1.000 & 1,000 & 5 & 1,000 \\
\hline $\mathbf{0 . 0 0 5 0}$ & 0.0050 & 1.000 & 1.000 & 1,000 & 10 & 1,000 \\
\hline
\end{tabular}

The resolution power is assessed by simulating different expected level of $F_{\mathrm{ST}}$ according to the effective population size $\left(N_{\mathrm{e}}\right)$ and generations $(\mathrm{t})$ and to Nei (1987) formula: $F_{\mathrm{ST}}=1-(1-$ $\left.1 / 2 N_{\mathrm{e}}\right)^{\mathrm{t}}$. The significance, evaluated using Fisher's exact tests as well as $\chi^{2}$ tests, reflects the power to detect any given level of differentiation (Average $F_{\mathrm{ST}}$ ) with the sampling design developed during our study. $N_{\mathrm{e}}$ values used during the test are based on estimates calculated from fisheries data. "Runs" denotes the number of simulation performed. The setting $F_{\mathrm{ST}}=0$ and $t=0$ estimates $\alpha$ (type I error; in the absence of genetic drift). 
Supplementary Table S6: Genetic differentiation among samples. Pairwise $F_{\mathrm{ST}}$ (above diagonal) and p-values (below diagonal) among 14 samples of Atlantic herring $C$. harengus based on allelic frequencies at 24 microsatellite loci. See Table 1 for sample codes.

\begin{tabular}{|c|c|c|c|c|c|c|c|c|c|c|c|c|c|c|}
\hline 1 & 0 & -0.0010 & -0.0008 & -0.0003 & 0.0006 & -0.0007 & -0.0003 & 0.0003 & 0.0008 & 0.0007 & $0.0074^{*}$ & $0.0127^{*}$ & $0.0106^{*}$ & $0.0110 *$ \\
\hline 2 & 0.998 & 0 & -0.0006 & -0.0004 & -0.0002 & 0.0001 & -0.0005 & -0.0001 & 0.0012 & -0.0004 & $0.0082 *$ & $0.0154 *$ & $0.0117^{*}$ & $0.0115^{*}$ \\
\hline 3 & 0.907 & 0.850 & 0 & -0.0002 & -0.0009 & -0.0008 & -0.0014 & 0.0001 & 0.0007 & -0.0013 & 0.0064* & $0.0124 *$ & $0.092 *$ & $0.0010^{*}$ \\
\hline 4 & 0.494 & 0.803 & 0.490 & 0 & 0.0005 & -0.0001 & -0.0001 & 0.0003 & 0.0011 & 0.0024 & $0.0087^{*}$ & $0.0150^{*}$ & $0.0122^{*}$ & 0.0116 \\
\hline 5 & 0.127 & 0.808 & 0.598 & 0.117 & 0 & -0.0005 & -0.0001 & 0.0011 & 0.0012 & 0.0015 & $0.0088^{*}$ & $0.0160^{*}$ & $0.0130^{*}$ & $0.0115^{*}$ \\
\hline 6 & 0.928 & 0.929 & 0.916 & 0.639 & 0.038 & 0 & 0.0009 & -0.0003 & 0.0001 & 0.0002 & $0.0082 *$ & $0.0115^{*}$ & $0.0122 *$ & $0.0122 *$ \\
\hline 7 & 0.972 & 0.951 & 0.986 & 0.590 & 0.310 & 0.957 & 0 & -0.0007 & -0.0001 & 0.0003 & $0.0073^{*}$ & $0.0113^{*}$ & $0.0093^{*}$ & $0.0101 *$ \\
\hline 8 & 0.138 & 0.811 & 0.720 & 0.024 & 0.038 & 0.912 & 0.972 & 0 & -0.0001 & 0.0008 & $0.0067^{*}$ & $0.0120 *$ & 0.0090* & $0.0092 *$ \\
\hline 9 & 0.097 & 0.766 & 0.549 & 0.122 & 0.018 & 0.332 & 0.497 & 0.014 & 0 & -0.0001 & $0.0074^{*}$ & $0.0127^{*}$ & 0.0121 * & $0.0122 *$ \\
\hline 10 & 0.112 & 0.783 & 0.989 & 0.001 & 0.006 & 0.359 & 0.155 & 0.416 & 0.083 & 0 & $0.0075^{*}$ & $0.0119^{*}$ & $0.0115^{*}$ & $0.0107 *$ \\
\hline 11 & 0.000 & 0.000 & 0.000 & 0.000 & 0.000 & 0.000 & 0.000 & 0.000 & 0.000 & 0.000 & 0 & $0.0182 *$ & $0.0079 *$ & $0.0069 *$ \\
\hline 12 & 0.000 & 0.000 & 0.000 & 0.000 & 0.000 & 0.000 & 0.000 & 0.000 & 0.000 & 0.000 & 0.000 & 0 & $0.0160^{*}$ & $0.0169 *$ \\
\hline 13 & 0.000 & 0.000 & 0.000 & 0.000 & 0.000 & 0.000 & 0.000 & 0.000 & 0.000 & 0.000 & 0.000 & 0.000 & 0 & 0.0022 \\
\hline 14 & 0.000 & 0.000 & 0.000 & 0.000 & 0.000 & 0.000 & 0.000 & 0.000 & 0.000 & 0.000 & 0.000 & 0.000 & 0.004 & 0 \\
\hline
\end{tabular}

Emboldened values differ significantly from zero (Fisher's exact test. $\mathrm{p}<0.05$ ).

$*$ Values remaining significant after Bonferroni correction $(\alpha=0.05 / 91=0.0005)$. 
Supplementary Table S7: Genetic differentiation among samples. Pairwise $F_{\mathrm{ST}}$ (above diagonal) and p-values (below diagonal) among 14 samples of Atlantic herring C. harengus based on allelic frequencies at Cpa111. See Table 1 for sample codes.

\begin{tabular}{|c|c|c|c|c|c|c|c|c|c|c|c|c|c|c|}
\hline & 1 & 2 & 3 & 4 & 5 & 6 & 7 & 8 & 9 & 10 & 11 & 12 & 13 & 14 \\
\hline 1 & 0 & -0.0066 & 0.0013 & -0.0020 & -0.0021 & -0.0038 & -0.0004 & 0.0011 & -0.0048 & 0.0023 & 0.0300 & 0.0054 & 0.1196 & 0.0965 \\
\hline 2 & 0.791 & 0 & -0.0087 & -0.0070 & -0.0067 & -0.0077 & 0.0018 & 0.0018 & -0.0102 & -0.0067 & 0.0282 & 0.0060 & 0.1234 & 0.1000 \\
\hline 3 & 0.636 & 0.891 & 0 & -0.0048 & -0.0024 & 0.0004 & 0.0137 & 0.0155 & -0.0052 & -0.0050 & 0.0266 & 0.0162 & 0.1367 & 0.1053 \\
\hline 4 & 0.616 & 0.313 & 0.445 & 0 & -0.0049 & -0.0022 & 0.0091 & 0.0109 & -0.0042 & -0.0002 & 0.0308 & 0.0135 & 0.1389 & 0.1078 \\
\hline 5 & 0.744 & 0.871 & 0.586 & 0.652 & 0 & -0.0020 & 0.0091 & 0.0137 & -0.0024 & 0.0035 & 0.0288 & 0.0177 & 0.1325 & 0.1041 \\
\hline 6 & 0.691 & 0.587 & 0.162 & 0.111 & 0.405 & 0 & 0.0044 & 0.0021 & -0.0050 & -0.0006 & 0.0427 & 0.0086 & 0.1435 & 0.1176 \\
\hline 7 & 0.756 & 0.566 & 0.408 & 0.136 & 0.164 & 0.083 & 0 & -0.0035 & 0.0010 & 0.0134 & 0.0263 & -0.0003 & 0.0836 & 0.0715 \\
\hline 8 & 0.424 & 0.483 & 0.217 & 0.124 & 0.110 & 0.261 & 0.517 & 0 & -0.0014 & 0.0084 & 0.0468 & -0.0038 & 0.1112 & 0.1002 \\
\hline 9 & 0.750 & 0.893 & 0.923 & 0.492 & 0.646 & 0.342 & 0.465 & 0.698 & 0 & -0.0048 & 0.0301 & 0.0031 & 0.1233 & 0.0998 \\
\hline 10 & 0.097 & 0.480 & 0.770 & 0.066 & 0.051 & 0.118 & 0.018 & 0.270 & 0.884 & 0 & 0.0440 & 0.0122 & 0.1620 & 0.1277 \\
\hline 11 & $0.000^{*}$ & $0.000^{*}$ & 0.007 & $0.000^{*}$ & $0.000^{*}$ & $0.000 *$ & $0.000^{*}$ & $0.000^{*}$ & $0.000^{*}$ & $0.000^{*}$ & 0 & 0.0371 & 0.0580 & 0.0334 \\
\hline 12 & 0.001 & 0.015 & 0.052 & 0.004 & $0.000^{*}$ & $0.000^{*}$ & 0.002 & 0.027 & 0.019 & 0.001 & $0.000^{*}$ & 0 & 0.1042 & 0.0890 \\
\hline 13 & $0.000^{*}$ & $0.000^{*}$ & $0.000^{*}$ & $0.000^{*}$ & $0.000^{*}$ & $0.000^{*}$ & $0.000 *$ & $0.000^{*}$ & $0.000^{*}$ & $0.000^{*}$ & 0.001 & $0.000^{*}$ & 0 & -0.0004 \\
\hline 14 & $0.000^{*}$ & $0.000^{*}$ & $0.000^{*}$ & $0.000^{*}$ & $0.000^{*}$ & $0.000^{*}$ & $0.000^{*}$ & $0.000^{*}$ & $0.000^{*}$ & $0.000^{*}$ & $0.000^{*}$ & $0.000^{*}$ & 0.320 & 0 \\
\hline
\end{tabular}

Emboldened values differ significantly from zero (Fisher's exact test. $\mathrm{p}<0.05$ ).

$*$ Values remaining significant after Bonferroni correction $(\alpha=0.05 / 91=0.0005)$. 
Supplementary Table S8: Results from the hierarchical Bayesian cluster analysis (STRUCTURE) based on all 24 microsatellite loci and all samples. STRUCTURE was run using 350,000 burn-in and 500,000 iterations for 10 independent runs for $K=1$ to 10 for the North Atlantic samples and from $K=1$ to 4 for the local Norwegian fjords (samples 11, 12, 13 and 14). An admixture model with correlated allele frequencies without prior information on sample location was implemented. Bold values indicate the most likely number of clusters.

\begin{tabular}{lccc}
\hline & $K$ & Mean LnP $(K)$ & StDev LnP $(K)$ \\
\hline North Atlantic & $\mathbf{1}$ & $\mathbf{- 8 7 1 0 2}$ & $\mathbf{0 . 2 8 9 8}$ \\
& 2 & -87261 & 12.7600 \\
& 3 & -87740 & 91.5819 \\
& 4 & -88410 & 95.0116 \\
& 5 & -89562 & 271.3621 \\
& 6 & -91281 & 799.5722 \\
& 7 & -93083 & 1390.0332 \\
& 8 & -95410 & 1819.3528 \\
& 9 & -95538 & 2152.4678 \\
& 10 & -95920 & 1641.7548 \\
\hline Local fjords (all) & 1 & -49481 & 2.0991 \\
& $\mathbf{2}$ & $\mathbf{- 4 8 8 2 9}$ & $\mathbf{5 . 9 3 2 6}$ \\
& 3 & -49195 & 180.2179 \\
& 4 & -49718 & 1186.7621 \\
\hline Local fjords (samples 11, 13 and 14) & $\mathbf{1}$ & $\mathbf{- 3 3 5 3 0}$ & $\mathbf{1 . 0 3 9 0}$ \\
& 2 & -33627 & 23.2868 \\
& 3 & -34463 & 254.8380 \\
\hline
\end{tabular}


Supplementary Table S9: Results from the hierarchical Bayesian cluster analysis (STRUCTURE) based only on neutral microsatellite loci and all samples. STRUCTURE was run using 350,000 burn-in and 500,000 iterations for 10 independent runs for $K=1$ to 10 for the North Atlantic samples and from $K=1$ to 3 for the local Norwegian fjords (samples 11, 13 and 14). An admixture model with correlated allele frequencies without prior information on sample location was implemented. Bold values indicate the most likely number of clusters.

\begin{tabular}{lccc}
\hline & $K$ & Mean LnP(K) & StDev LnP(K) \\
\hline North Atlantic & $\mathbf{1}$ & $\mathbf{- 8 5 8 1 7}$ & $\mathbf{0 . 1 8 7 1}$ \\
& 2 & -85981 & 25.6621 \\
& 3 & -86425 & 74.1802 \\
& 4 & -87096 & 124.9924 \\
& 5 & -88564 & 489.7930 \\
& 6 & -90622 & 1073.9283 \\
& 7 & -92667 & 2955.3703 \\
& 8 & -94162 & 2935.9272 \\
& 9 & -96560 & 3065.5698 \\
& 10 & -97251 & 3204.5460 \\
\hline Local fjords & $\mathbf{1}$ & $\mathbf{- 3 2 9 1 9}$ & $\mathbf{0 . 6 5 7 9}$ \\
& 2 & -32999 & 21.2130 \\
& 3 & -33709 & 251.2843 \\
\hline
\end{tabular}



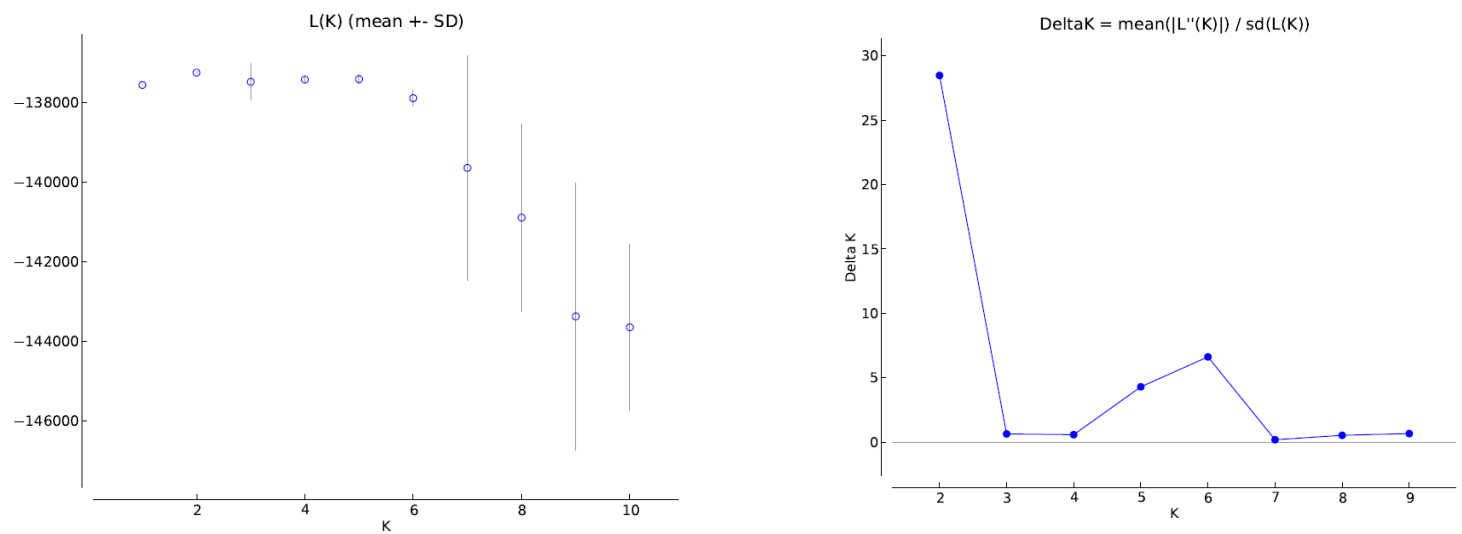

Supplementary Fig. S1: Results of the Bayesian cluster analysis performed in Structure for all microsatellite loci and all samples. Two clusters were detected both at the $\operatorname{LnP}(K)$ (left figure) and $\Delta K$ levels (Right figure). STRUCTURE was run using 350,000 burn-in and 500,000 iterations for 10 independent runs for $K=1$ to 10 using an admixture model with correlated allele frequencies. No prior information on sample location was implemented.
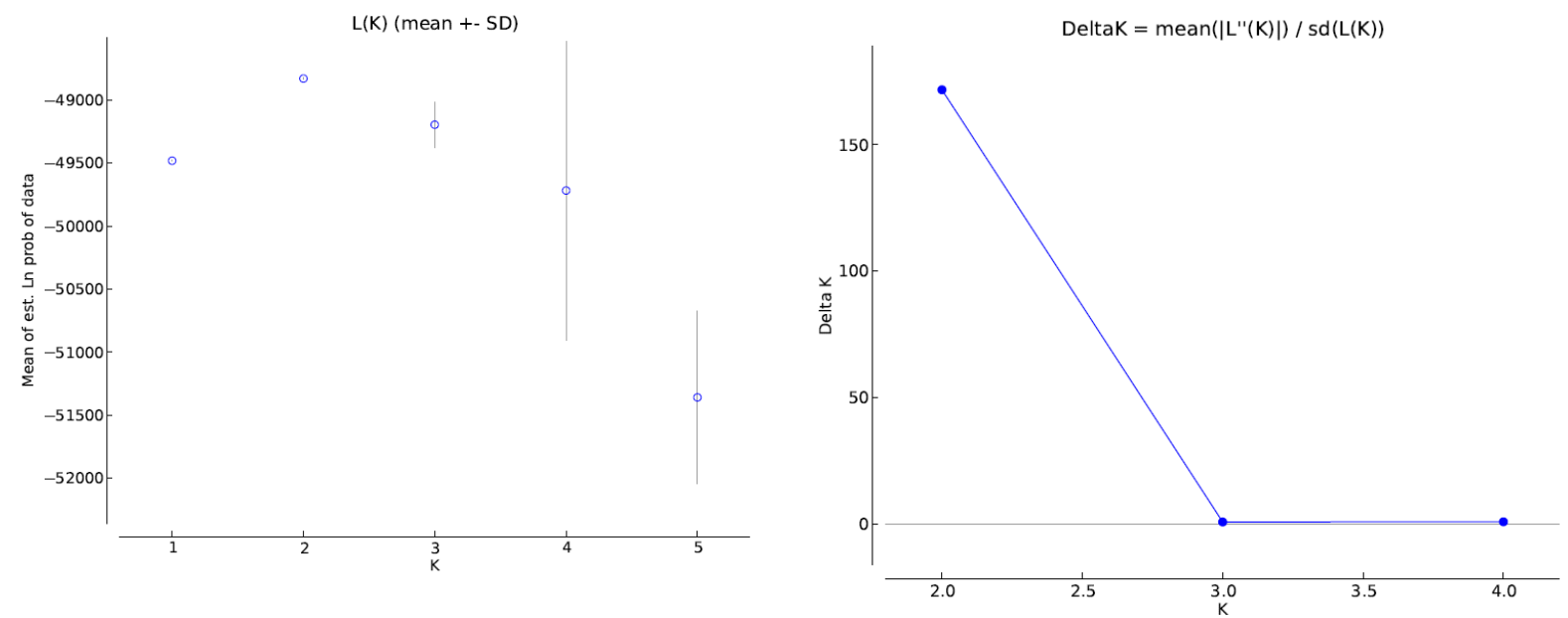

Supplementary Fig. S2: Results of the Bayesian cluster analysis performed in Structure for all microsatellite loci and the fjord samples. Two clusters were detected both at the $\operatorname{LnP}(K)$ (left figure) and $\Delta K$ levels (Right figure). STRUCTURE was run using 350,000 burnin and 500,000 iterations for 10 independent runs for $K=1$ to 5 using an admixture model with correlated allele frequencies. No prior information on sample location was implemented. 

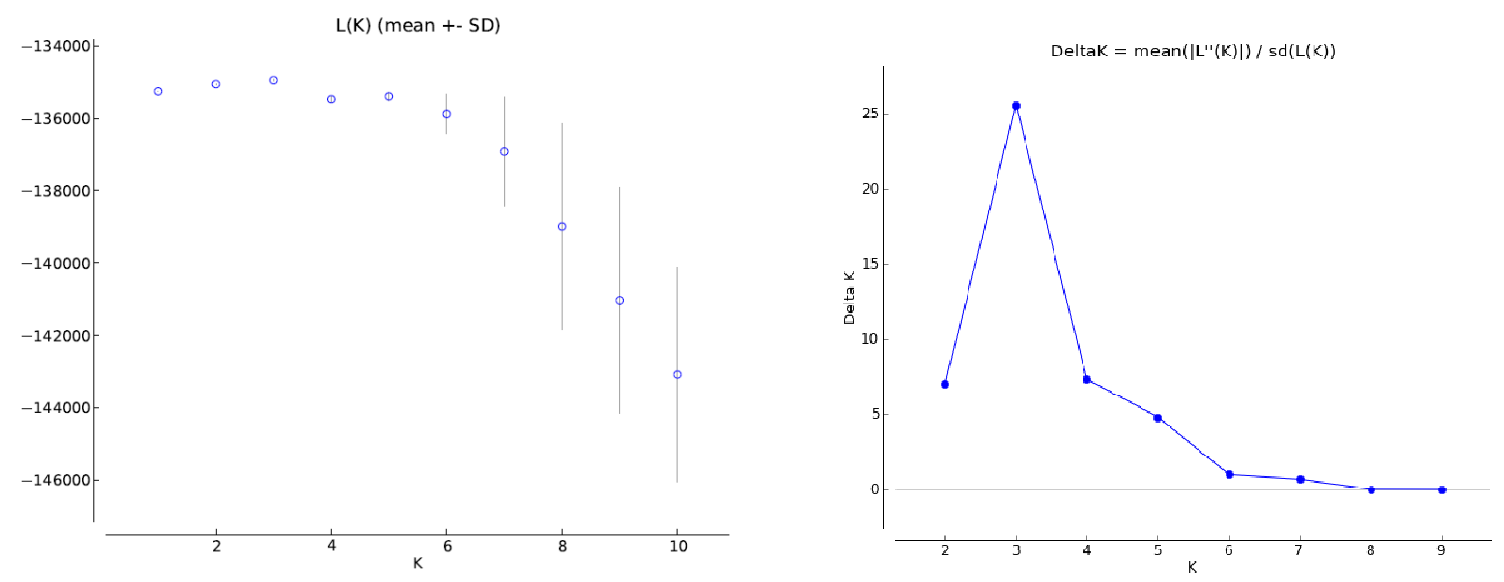

Supplementary Fig. S3: Results of the Bayesian cluster analysis performed in Structure for neutral microsatellite loci only and all samples. Three clusters were detected both at the $\operatorname{LnP}(K)$ (left figure) and $\Delta K$ levels (Right figure). STRUCTURE was run using 350,000 burnin and 500,000 iterations for 10 independent runs for $K=1$ to 10 using an admixture model with correlated allele frequencies. No prior information on sample location was implemented. No additional clusters were detected. 